\title{
The Role of Local Institutions in Adaptation to Climate Change
}

IFRI Working Paper \# W08I-3

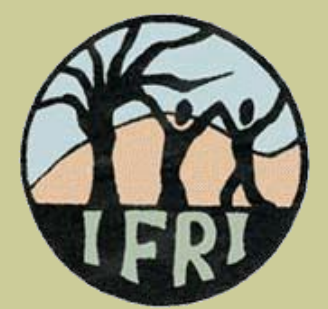

INTERNATIONAL FORESTRY RESOURCES AND INSTITUTIONS PROGRAM

School of Natural Resources and Environment

University of Michigan

440 Church Street, MI 48109

Phone: 734-764-9542

Fax: 734-647-5047

http://www.umich.edu/ ifri/
Arun Agrawal

School of Natural Resources and Environment University of Michigan 


\title{
The Role of Local Institutions in Adaptation to Climate Change ${ }^{1}$
}

\author{
Arun Agrawal ${ }^{2}$ \\ Phone: 7346475948 \\ Email: arunagra@umich.edu
}

\footnotetext{
${ }^{1}$ Paper prepared for the Social Dimensions of Climate Change, Social Development Department, The World Bank, Washington DC, March 5-6, 2008.

${ }^{2}$ Special thanks to Nicolas Perrin, Andrew Norton, Robin Mearns, Mafalda Duarte, Gretel Gambarelli, Catherine McSweeney, Paul Siegel, Jesse Ribot, Neil Adger, Erin Carey, Rachel Kornak, Julien Labonne, Daniel Miller, Nilufar Ahmad, and participants at the "Are there Limits to Adaptation" Conference in February 2008 in London.
} 


\section{EXECUTIVE SUMMARY \\ THE ROLE OF LOCAL GOVERNANCE AND INSTITUTIONS IN LIVELIHOODS ADAPTATION TO CLIMATE CHANGE}

Climate change will be pivotal in redefining development in the twenty-first century. How nations, societies, communities, and households respond to the impacts of climate changes and variability to which the world has already been committed will in many instances determine their prospects for growth, equity, and sustainability. Given the potential magnitude of impending changes in institutional and social relationships, the gaps in current knowledge about the role of institutions in adapting to climate change are remarkably large.

This review focuses on the role of local institutions in adaptation to climate change. It does so under the belief that climate impacts will affect disadvantaged social groups more disproportionately, and that local institutions centrally influence how different social groups gain access to and are able to use assets and resources. It suggests that adaptation to climate change is inevitably local and that institutions influence adaptation and climate vulnerability in three critical ways: a) they structure impacts and vulnerability, b) they mediate between individual and collective responses to climate impacts and thereby shape outcomes of adaptation, and c) they act as the means of delivery of external resources to facilitate adaptation, and thus govern access to such resources.

In focusing on local institutions, the review fills two glaring gaps in existing understandings about institutions and climate change: the lack of middle-range theories of adaptation practices to help frame policy debates, and the absence of comparative empirical studies of adaptation to support policy interventions. Existing scholarship has typically attempted either to develop insights at the global level in an effort to mimic the scholarship on mitigation and climate modeling or been concerned with localized and specific case studies of vulnerability and responses to climate.

To contribute to middle-range theoretical knowledge about climate change the review develops $\underline{\mathrm{a}}$ conceptual framework to understand and classify the adaptation practices of the rural poor, view the institutional structuring of adaptation, and examine the types of external support interventions that local institutions inevitably channel. To contribute to comparative studies of local adaptation and institutions, the paper first examines more than 100 cases of local adaptation to assess the applicability of the proposed conceptual framework, applies the lessons of this analysis to the ongoing National Adaptation Programmes of Action, and finally draws some preliminary implications of the work for different types of development projects.

The review proposes a focus on different forms of mobility, storage, diversification, communal pooling, and exchange in rural settings as the basic mechanisms through which households address riskiness of livelihoods.

Using the familiar typology of public, private, and civil society institutions the review proposes an institutional linkages framework that highlights the role of institutional partnerships in facilitating adaptation and drawing from social network analysis it presents a conceptual toolkit to analyze institutional partnerships and their impacts on resource access of vulnerable social groups.

In examining the role of institutions in channeling financial, information and technological, leadership, and policy interventions into rural areas, the review highlights that institutions are critical leverage points through which to determine the direction and magnitude of flows of resources to different social groups.

The above analysis leads to six conclusions with respect to the role of local institutions in facilitating adaptation, needs for future research, and the importance of institutional analysis for development projects.

\section{Support greater role for institutional partnerships in facilitating adaptation}

Institutional partnerships are crucial to local adaptation practices. Support for such partnerships can greatly enhance informal institutional processes through which adaptation occurs. Partnerships among local public and civil society institutions are associated more closely with adaptation practices related to diversification 
and communal pooling. Partnerships between private and civil society institutions are relatively uncommon and need greater encouragement. They tend to be more closely associated with exchange and storage based adaptation practices. Mobility, although often neglected in the literature on adaptation is essential to deal with high levels of climate variability.

\section{Enhance local institutional capacities}

Although local institutions play a critical role in supporting adaptation, the intensity of adverse future climate impacts is likely to increase - thereby also increasing vulnerability and reducing existing adaptive capacity. External interventions in the form of new information and technology aimed at improving coping capacities, institutional coordination for better articulation (connections among institutions) and improved access (connections of institutions with social groups), and inflows of finances support for local leadership will be critical to strengthen local institutional capacities.

Understand local institutional articulation and access patterns before providing resource support in any development project

Different social groups and individual households have varying levels of access to existing institutions. Vulnerable groups in general have lower institutional access than do those who are more powerful or better off. Before external support for greater adaptive capacity is made available, therefore, an analysis of the nature of institutional linkages and access for different social groups becomes critical. Only after a clear understanding of such relationships is available should particular institutions are selected as intermediaries for channeling resources.

\section{Improve institutional coordination across scales}

Existing national plans for adaptation seem to have attended only in a limited fashion to the role of local institutions in designing, supporting, and implementing adaptation. However, if adaptation is inevitably local, there is a great need to involve local institutions more centrally in planning for and implementing adaptation policies and projects. At the very least, there must be far greater coordination between adaptation policies and measures adopted by institutions and decision makers at the national level, and their counterparts at the local level.

Focus on territorial development strategies taking both vulnerabilities and capacities into account Interventions for improving adaptive capacity in the context of development projects need to attend better to adaptation practices facilitated by different forms of external support. The multiple linkages among external interventions and local adaptations can only be understood through a focus on the mediating role and linkages among different institutions in a given territory, and their influence on production and adaptation possibilities.

\footnotetext{
Adopt an adaptive perspective on institutional development

As climate change and its impacts become more obvious, it is increasingly important to integrate concerns for managing risks faced by households and communities into earlier concerns for growth, poverty alleviation, equity, and sustainability. The paper refers to the need for integrating climate risk management in development as adaptive development. Adaptive development will require a greater role for local institutions in both planning and implementation of development projects. Because the state of knowledge is sparse about the most effective ways in which institutions can facilitate local adaptation, no blueprints can be advanced for planning adaptive development. An adaptive perspective on development will require the willingness to experiment, capacity to take the risk of making mistakes, and flexibility to make space for social and institutional learning.
} 


\section{Glossary for Key Terms Used in the Paper ${ }^{3}$}

Adaptation: actions and adjustments undertaken to maintain the capacity to deal with stresses induced as a result of current and future external changes (Nelson et al. 2007:396, Alland 1975).

Adaptive Capacity: preconditions that enable actions and adjustments in response to current and future external changes; dependent both on social and biophysical elements (Nelson et al. 2007: 397).

Community: group of individuals united by commonality of purpose, characteristics, beliefs, and/or actions. Most communities are also internally differentiated (Agrawal and Gibson 1999).

Coping: use of existing resources to achieve various desired goals during and immediately after unusual, abnormal, and adverse conditions of a hazardous event or process. The strengthening of coping capacities, together with preventive measures, is an important aspect of adaptation and usually builds resilience to withstand the effects of natural and other hazards.

Decentralization: downward redistribution of resources, responsibilities, and decision-making powers in a territorial and administrative hierarchy.

\section{Environmental Risks:}

Institutions: humanly created formal and informal mechanisms that shape social and individual expectations, interactions, and behavior (Ostrom 1990, North 1990, Bates 1981). Institutions structure and shape outcomes through the actions of individuals and decision makers associated with them. To understand their impacts it is necessary to examine their internal processes, external relationships, and linkages with different social groups and households.

Institutional Access: degree to which households and different social groups in a given location are connected to institutions and have the ability to gain institutional benefits as a result of such connections.

Institutional Articulation: extent to which different institutions in a given territory are linked to each other, and the nature of such linkages.

Livelihoods: comprise the capabilities, and material and social assets necessary for a means of living; includes the idea of coping with and recovery from external stresses (Carney 1998, Chambers and Conway 1992, Scoones 1998), and the sustainability of the resource base on which livelihoods depend (Ashley and Carney 1999, Norton and Foster 2001).

Mitigation: actions and policies that reduce exposure to climate change, for example, through regulation and institutional changes, technological shifts, alterations in behaviors, or change in location (Nelson et al. 2007).

Organizations: concrete manifestation of institutions with an identifiable location, personnel, and rule structure. For this paper, classifiable into three broad, sometimes overlapping sectors: public (bureaucratic administrative units, and elected local governments), civic (membership and cooperative organizations), and market sectors (service and business organizations) (Uphoff and Buck 2007: 47).

\footnotetext{
${ }^{3}$ The definitions provided in the glossary are drawn from a broad selection of literature on climate change and adaptation. Because the field is growing rapidly, many of the definitions remain works in process. A number of other World Bank documents and papers place somewhat different emphases on the key terms used in this paper, partly because of the differing emphases and purposes. See, for example, Heltberg et al. 2008, and World Bank, forthcoming.
} 
Resilience: the amount of change a system can undergo and still retain the same function and structure while retaining options to develop in desired directions (Berkes et al. 2003, Holling, 1973, Nelson et al. 2007).

Territorial Development: an approach to development focusing on productive transformation of agricultural and non-agricultural activities in a well-defined distinct territory through institutional development that links people, local governments, economic and civil society organizations, and higher level government institutions (de Janvry and Sadoulet 2004). The heterogeneity of territories necessitates careful modulation of public policies to meet the needs of affected parties in a given territory.

Terroir: a socially and geographically defined space within which community resources and associated rights are located in order to satisfy their needs (FAO 2003).

Vulnerability: the susceptibility of a system to disturbances and loss, determined by exposure to perturbations, sensitivity to perturbations, and the capacity to adapt (Smit and Wandel 2006). The nature of perturbations (slow onset or sudden and episodic) and the location of the system in the risk cycle are crucial in shaping vulnerability. 
TABLE OF CONTENTS

GLOSSARY

EXECUTIVE SUMMARY

1. INTRODUCTION

2. Climate Change, Development, and Adaptation

2.1 DEVElopMENT, ADAPTIVE CAPACITY, AND ADAPTATION

2.2 CLIMATE-SPECIFIC ADAPTATION

2.3 IMPACTS OF CLIMATE CHANGE AND VULNERABILITY

3. ClimATE IMPACTS ON LIVELIHOODS AND TYPES OF ADAPTATION

3.1 HISTORICAL EXPERIENCES OF ENVIRONMENTAL RISKS AND VULNERABILITY 3.2 ClASSES OF ADAPTATION PRACTICES AND THEIR CHARACTERISTICS

3.3 DETERMINANTS OF ADAPTATION PRACTICES

4 RURAL LOCAL INSTITUTIONS AND ADAPTATION TO CLIMATE CHANGE

4.1 CLASSIFYING LOCAL INSTITUTIONS RELEVANT TO ADAPTATION

4.2 HOW DO LOCAL INSTITUTIONS AND ORGANIZATIONS AFFECT ADAPTATION AND LIVELIHOODS

4.3 INSTITUTIONAL LINKAGES: ACCESS AND ARTICULATION

4.4 FEATURES OF EFFECTIVE LOCAL INSTITUTIONS FOR CLIMATE ADAPTATION

4.5 BRINGING THE STRANDS OF THE ARGUMENT TOGETHER

5 EXTERNAL INTERVENTIONS AND LOCAL INSTITUTIONS

6 AdAPTATION, INSTITUTIONS, AND LIVELIHOOdS FRAMEWORK: CASE EVIDENCE

6.1 ANALYSIS AND OBSERVATIONS OF THE UNFCCC DATA

6.2 DISCUSSION OF THE NAPA CASES

7. RELEVANCE OF THE ANALYSIS AND THE FINDINGS FOR WORLD BANK OPERATIONS

8 CONCLUSIONS

REFERENCES

NOTES 
The Role of Local Governance and Institutions in Livelihoods Adaptation to Climate Change

Arun Agrawal

\section{Introduction}

The most important implications of climate change from the perspective of the World Bank concern its potentially disastrous impacts on the prospects for development, especially for poorer populations in the global South. Earlier writings on climate change had tended to focus more on its links with biodiversity loss, spread of pathogens and diseases, land use planning, ecosystem change, and insurance markets, rather than its connections with development (Easterling and Apps 2005, Harvell et al. 2002, Tompkins and Adger 2004). But as the Social Development Department of the World Bank recently noted, "Climate change is the defining development challenge of our generation" (SDV, 2007: 2). These words echo the World Bank President Robert Zoellick's statement at the United Nations Climate Change Conference in 2007 in Bali where he called climate change a "development, economic, and investment challenge." Indeed, understanding the relationship between climate change, the human responses it necessitates, and how institutions shape such responses is an increasingly urgent need. This report directs attention towards a subset of such relationships, focusing on rural institutions and poor populations in the context of climate variability and change-induced adaptations.

It is critically important to understand better the role of institutions in shaping adaptation, especially the role of local institutions, if adaptation to climate change is to help the most vulnerable social groups. Not only have existing institutions affected how rural residents responded to environmental challenges in the past, they are also the fundamental mediating mechanisms that will translate the impact of external interventions to facilitate adaptation to climate change. Institutional arrangements structure risks and sensitivity to climate hazards, facilitate or impede individual and collective responses, and shape the outcomes of such responses. Understanding how they function in relation to climate and its impacts is therefore a core component in designing interventions that can positively influence the adaptive capacity and adaptation practices of poor populations.

Attending to the role of institutions has become especially important as climate change and its impacts move from being the pet obsession of a few atmospheric scientists to becoming the subject of both dinnertime conversations and intense scholarly exchanges. The changing politics of climate change and adaptation, and the relevance of climate change to development trajectories is a result of the extraordinary diverse ways in which climate change will produce ubiquitous effects (Chopra et al. 2006).

Indeed, the concern about climate change is pervasive because of the all-encompassing and multidimensional nature of climate impacts. Droughts, higher temperatures, flooding, sea-level rise, heat waves, more intense storms, and greater uncertainty in weather patterns translate into more widespread diseases, greater biodiversity loss, crop losses, and system transformations which in turn imply major social and economic dislocations and threats to livelihoods of the poor. The impacts of climate change are likely to be especially severe in social and ecological contexts of arid and semi-arid regions, colder and polar areas, and coastal locations where livelihoods are often already stressed and additional adverse biophysical and social changes can be overwhelming.

The popular consensus on the reality of climate change, its human causes, and the severity of its impacts may not be very old, ${ }^{1}$ but most scholarly and policy literature holds that poor, natural resourcedependent rural households will bear a disproportionate burden of adverse impacts (Kates 2000,

Mendelsohn et al. 2007, Ribot et al. 1996, Smith et al. 2003, and Thomas and Twyman 2006). Certainly, in many parts of the world, these effects are already in play with potentially disastrous consequences for the poor (Adger et al. 2005, Adger et al. 2007). But the rural poor ${ }^{2}$ have also successfully faced threats linked to climate variability in the past, even if climate change likely increases the expected frequency and intensity of such threats (Mortimore and Adams 2001, Scoones 2001). Whether historically developed adaptation practices among the rural poor will be successful depends crucially on the nature of prevailing formal and informal rural institutions.

Historical experience and knowledge about adaptation possibilities is critical to future policy formulations regarding adaptation. This is because the specific nature of climate change impacts continues to be uncertain, especially for small territorial units, ${ }^{3}$ even as it is evident that the general impacts of climate change will be striking and long lasting if current trends continue. Future efforts to address climate 
change and craft strategic initiatives to enhance rural poor's adaptive capacity can therefore profitably examine historical adaptive responses, their institutional context and correlates, and the role of institutions in facilitating adaptation. Indeed, documenting, understanding, and learning from past institutional experiences and crafting interventions that strengthen historically proven collective efforts and institutions is a critical first step. It is also potentially one of the most effective mechanisms in the multi-stranded effort to address the adverse drastic as well as long-term impacts of climate change.

The paper develops its argument about the role of institutions by proposing an analytical classification of historically observed adaptation practices. It then uses the familiar distinction between public, civic, and private domains and insights from the literature on network analysis to survey important recent writings work on adaptation, and outlines a framework through which to view the relationship between adaptation due to climate change, livelihoods of the rural poor, and the role of institutions in facilitating external support for adaptation. ${ }^{4}$ The Adaptation, Institutions and Livelihoods Framework in figure 1 shows the critical role of institutions in thinking about climate change and adaptation. Institutions structure the impacts of climate risks on households in a given ecological and social context, and shape the degree to which the responses of households are likely to be individually or collectively oriented. They also mediate the influence of any external interventions on adaptation practices. The exact manner in which institutions generate these effects depends on a large variety of factors, among them the nature and severity of climate events and trends, the local context and household and community endowments, the larger set of social and political factors within which institutions function, and obviously, the interests of those whose decisions and actions institutions translate into actions and outcomes.

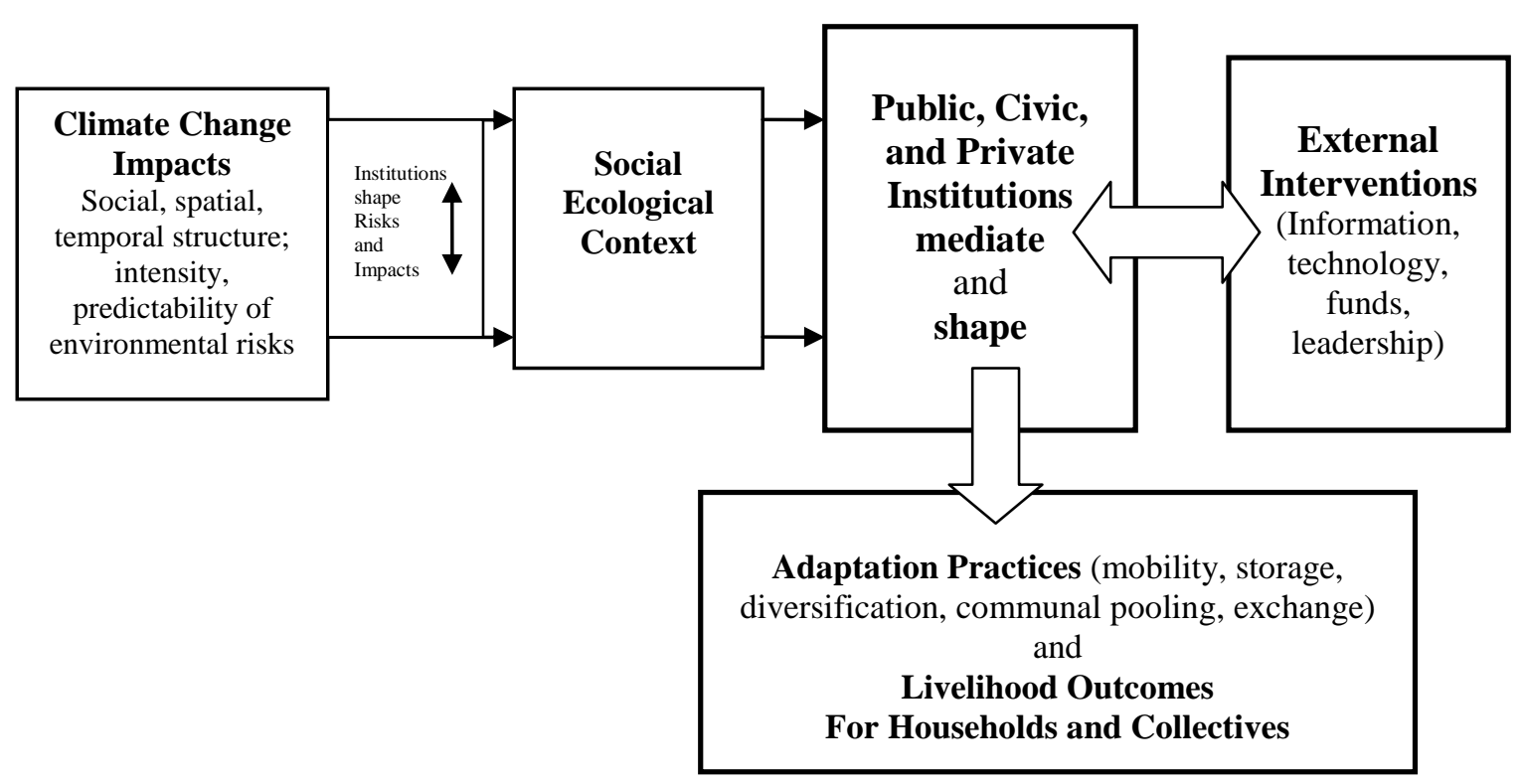

Figure 1: Adaptation, Institutions, and Livelihoods Framework

After examining the relationships between climate related vulnerabilities, adaptation practices, institutions, and external interventions, the paper applies the AIL analytical framework to nearly 300 cases of adaptation practices drawn from the UNFCCC's coping strategies database, and the most desired adaptation projects selected by nearly 15 countries in their National Adaptation Programmes of Action. It thus shows how local rural institutions can serve as anchors and scaffolding to reinforce the adaptive capacity and adaptation practices of the rural poor. The lessons from this discussion are finally applied to 
three different types of World Bank climate-related projects to draw out the operational significance of institutional analysis in the context of climate change.

\section{Climate Change, Development, and Adaptation}

The core manifestations of climate change comprise gradual changes in mean temperatures and precipitation, greater range in seasonal and inter-annual variation, increased frequency and intensity of extreme events, and potentially catastrophic transformations of ecosystems (Tompkins and Adger 2004). These manifestations will correlate with both slow-onset hazards such as erratic rainfall, sea level rise, water table changes, and increasing temperatures, and rapidly unfolding phenomena such as droughts, floods, failure of rains and crops, and storm. They will lead to greater exposure and sensitivity (see glossary) of rural populations through three major impacts on their livelihoods: increase in environmental risks, reduction in livelihoods opportunities, and in consequence, greater stresses on existing social institutions.

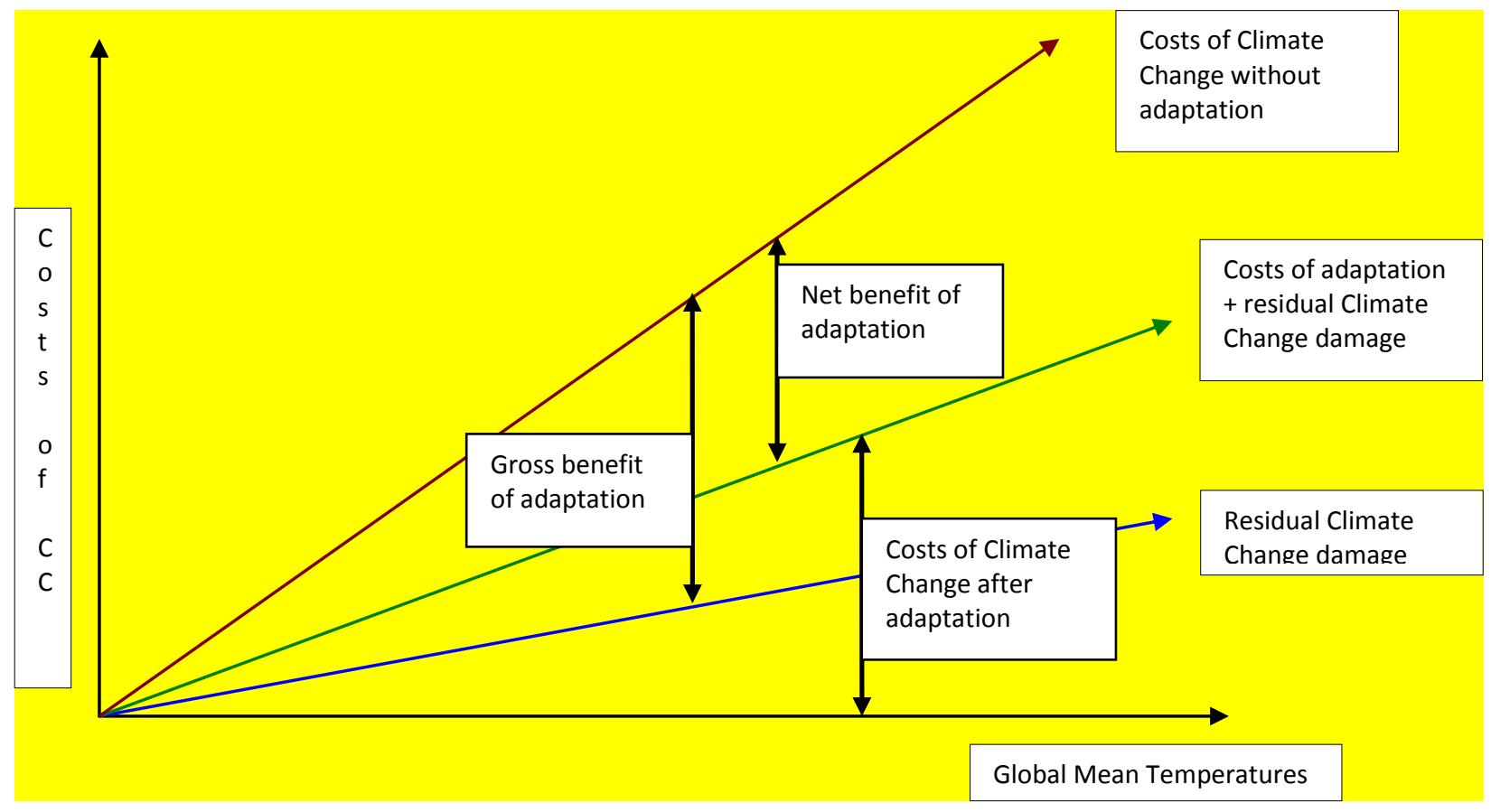

Figure 2: Stylized Relationship between Costs of Adaptation and Climate Change (from Stern Review, 2006).

Because of the lagged relationship between emissions and their future impacts, past and current emissions have already committed the planet to appreciable changes in climate. No matter the scope of future mitigation efforts, therefore, adaptation is necessary to reduce the impact of committed changes in climate. The greater the delay in lowering emissions to a point where they are no greater more than the capacity of the planetary carbon sinks to absorb, the stronger will be the need for more wide-ranging adaptations. Given that current emissions are somewhere between three and five times the absorptive capacity of the planet and a resolution to negotiations on global emissions is urgent but nowhere in sight, planning for adaptation continues to become increasingly urgent. At the most general level, then, adaptation is necessary because some climate change, with attendant effects on human existence, is already inevitable.

But beyond the inevitability of changes in climate, planning for and implementing strategies to promote adaptation is necessary for four additional reasons (see figure 1 above): increasing knowledge about future impacts of climate change (IPCC 2007b), existing experience of historical forms of adaptation which provide strategic lessons about the suitability of different forms of adaptation in different contexts (Adger et al. 2005, Finan and Nelson 2001), potentially larger negative social, economic, and ecological 
effects of unplanned adaptation (Adger et al. 2006), and potentially greater costs of adaptation, especially for poorer populations, the longer the delays in initiating adaptation. ${ }^{5}$

\subsection{Development, Adaptive Capacity and Adaptation}

Adaptation to climate impacts will necessitate changes in response to multiple types of stresses, across multiple scales, and by many actors who may sometimes work at cross-purposes. Learning from past experiences and planning adaptive responses is therefore especially important in the context of development. Indeed, development strategies, focusing successively over the past half century on growth, equity, and/or sustainability need also to incorporate adaptive concerns to be of relevance to the increased risks that climate change poses. The problems of poverty, inequality and oppression, and resource overuse to which development as growth, as equity, and as sustainability has been a solution are pertinent to address several dimensions of vulnerability of marginal populations. But it is also possible to address these problems, especially poverty and inequality, without sufficiently attending to vulnerabilities related to a lack of resilience and adaptive capacity.

Consider a familiar example. A climate-related shock to livelihoods, e.g. a drought in a semi-arid region, has the potential to devastate the livestock owned by a household. Development interventions that increase the milk or meat yields from herds without increasing their capacity to survive in the face of fluctuations in fodder availability can potentially increase total yield for the herd owner, but fail to smooth fluctuations across time periods. In the same agro-ecological context, privatization of land parcels can increase tenure security and encourage landowners to invest in the improvement of territorial infrastructure. But improvements may yield indifferent returns because of spatial and temporal fluctuations in rainfall that exacerbate household and community level vulnerability. However, if land is under open access in dry seasons, livestock-owning households can migrate to take opportunistic advantage of areas where forage is available - indeed, this is the strategy many of them use in drier areas of Sub-Saharan Africa, Mongolia, and western India (Agrawal 1999). On the other hand, development of drought resistant breeds of cattle, and land tenure regimes that permit mobility can lead to lower overall output in terms of fodder, milk, or meat, but also go together with greater capacity to withstand climatic variability.

Indeed, one of the more likely impacts of climate change is greater climate variability. With increasing climate variability, development interventions that do not attend to vulnerability, adaptive capacity, and resilience may end up worsening the situation of those they seek to benefit (see box 1). Efforts to address vulnerability of the poor and to improve adaptive capacity require deeper attention to institutions at multiple scale, and careful planning to ensure that institutions can work to help poorer groups who are most at risk from increasing volatility in climate phenomena and their human impacts. They live close to subsistence margins, and variations in earnings and livelihoods capabilities are far more likely to plunge them below the margin in comparison to the relatively well off who can draw upon a variety of capitals, assets, and institutional networks in times of stress.

\footnotetext{
Box 1: Development Strategies and Climate Change Effects

Since the mid-1940s, development interventions have tried to address specific goals of social change: growth, growth with equity, and sustainability. These goals of development interventions have broadly attempted to ameliorate the problems of poverty and underdevelopment, inequality, and resource scarcities/pollution. Impending climate change makes it necessary that development policy-makers and practitioners attend to a new set of problems related to climate risks and vulnerability.

Climate change, through changes in temperature and precipitation, can produce four major classes of impacts on rural livelihoods. These are indicated in the figure below through four illustrative curves denoted by a) low variability, high predictability (LVHP - green, solid curve); b) low variability, low predictability (LVLP - red, dotted curve); c) high variability, high predictability (HVHP - yellow, solid curve); and d) high variability, low predictability (HVLP - blue, dotted curve). Development strategies that continue to focus on ameliorating poverty, inequality, and resource scarcities are likely also to be at least somewhat effective in addressing climate change effects that are characterized by high predictability.
} 


\section{Forms of Environmental Variability}

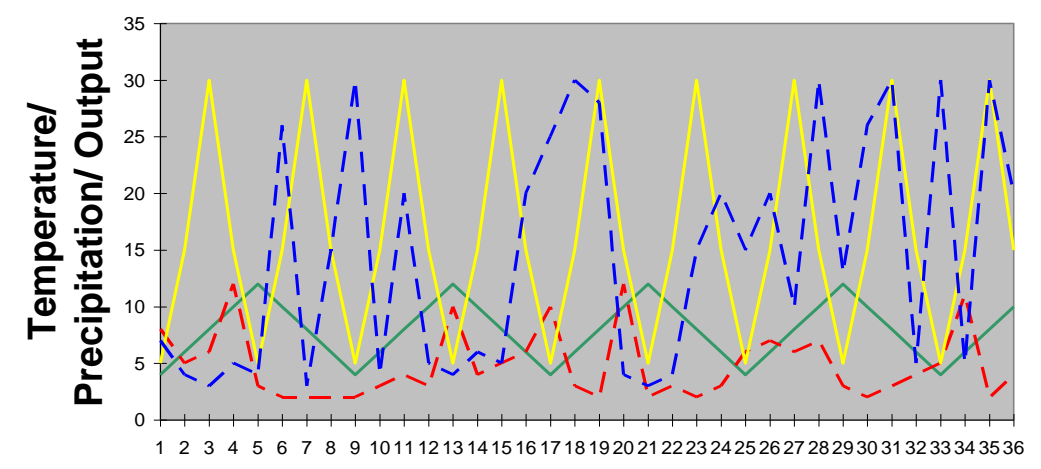

Time

\section{- LVHP - - LVLP - HVHP - - HVLP}

But without explicitly attending to adaptation and adaptive capacity, existing development strategies are likely to founder when confronting climate change that affects livelihoods significantly and unpredictably. This differentiation is especially important in view of the fact that many observers of climate point specifically to elements of discontinuity, irreversibility, and surprise in future climate change impacts.

In considering climate impacts it is necessary to attend to their frequency, periodicity, intensity, and timing to understand how they impact adaptive capacity. The dynamics of risk exposure can be crucial in determining both the sensitivity and adaptive capacity of social groups and households. Repeated and unpredictable exposure to risks can drastically reduce the ability of even households with high adaptive capacity to cope or respond effectively to risks. Thus the adaptive capacity of a household or community may be significantly depleted as a result of a recent major shock to its livelihoods and assets; similarly, communities and households that face regular occurrences of particular climate hazards are more likely to have developed adaptive responses over time as long as the scale of the hazard is not such as to wipe them out (Davies 1996).

\subsection{Climate-Specific Adaptations}

Adaptation has had a complex history even as it has come to be broadly accepted to signify the ways in which human societies will need to adjust to climate change. Adaptations to environmental risks, including those associated with climate change are especially necessary in regions that are already ecologically stressed. These include drylands and semi-arid areas, low-lying coastal regions, and colder and mountain environments. This review focuses especially on semi-arid and coastal environments in light of the available data.

Increasing temperatures, greater precipitation, more extreme events, and greater variability in them mean that agriculture-based livelihoods in drier parts of the world will likely require major technological inputs as well as significant institutional adjustments. As the variability of rainfall and mean temperatures increase, semi-arid regions will experience higher levels of land degradation, crop damage and failure, livestock deaths, and wildfires. Increased water and heat stress will also lead to greater risks of food and water shortage, malnutrition, health problems, and forced migration.

Low-lying coastal areas, especially islands are similarly exposed to significantly greater threats.

These include more intense storms and coastal flooding, and higher risks of coastal erosion and inundation. With sea-level rise it is likely that there will be more frequent devastating storm surges. These phenomena are projected to lead to a loss of more than a third of coastal wetlands around the globe, greater erosion of beaches, higher levels of coral bleaching, and the possibility of greater salinity in coastal freshwater systems. Collectively, millions of households in coastal areas may be devastated because of damage to infrastructure, settlements, and facilities necessary for life and livelihoods. Since many coastal areas support very high densities of human population, permanent relocation of human settlements may prove generally infeasible. Climate change will therefore require significant investments in infrastructure facilities but also extensive institutional buffering in the wake of disasters. 
It is worth noting that much of the current work on options for adaptation in semi-arid and lowlying coastal areas has tended to devote far greater attention to technological and infrastructure alternatives for reducing vulnerabilities and enhancing adaptive capacity at the expense of attending to social or institutional alternatives. Take as an example the IPCC Fourth Assessment Report (AR4) which examines adaptation options in coastal regions and their costs. Even as it locates impediments to adaptation in such factors as social resistance to change, weak governance, fragmented and ineffective institutional arrangements, inadequate knowledge of coastal conditions, lack of information on key vulnerability indicators and absence of data on existing indicators goes on to talk about embankments, dykes, flood proof buildings, sand dune replanting, levees, and sea walls as the measures needed for adaptation (Nicholls et al 2007: 340-44). However, such infrastructure enhancement measures may prove both more costly and less effective than efforts which combine governance and institutional interventions with technical and capital improvements.

What is also important from an adaptive development perspective is that without adequate attention to the institutional and social contexts of technical or infrastructure interventions, the likelihood is very high that richer, more powerful agents will appropriate the benefits of such interventions. The history of development interventions for the past half century suggests that even when development projects are specifically designed with the poor in mind, better-off groups often end up benefiting disproportionately. When the interests of the poor are not considered explicitly, they are even more likely to produce inequitable outcomes. It is therefore critically important to examine the institutional and social linkages of adaptation interventions even when such interventions are only technical or capital-intensive in nature. Indeed, at present the state of knowledge about how technological, capital, and institutional interventions may be combined cost effectively is far from satisfactory.

\subsection{Impacts of Climate Change on Vulnerability}

Most recent studies on climate change have drawn on earlier work on vulnerability (Bohle et al. 1994, Cutter 1996, Watts and Bohle 1993) and highlighted the fact that vulnerability to climate change is a function not just of biophysical outcomes related to variations and changes in temperature, precipitation, topography and soils, but also of socio-political and institutional factors that can vary significantly at a relatively fine scale (Adger 2006). Structural and group characteristics such as gender, caste, race, ethnic affiliation, indigeneity, and age, even when they are not consistent predictors are often closely related with vulnerability. The degree to which they are associated with vulnerability tends to depend on location- and culture-specific factors -- thus although climate change is a global phenomenon, adaptation to climate impacts is inevitably and unavoidably local.

It is thus not surprising that variation in greenhouse gas levels, average temperatures, and mean precipitation hides a diversity of impacts across regions, localities, and social groups within localities. This is because even if different areas within a region are exposed to the same climate risks, the sensitivity and vulnerability of different groups to climate impacts varies enormously depending on their institutional links, material endowments, occupational patterns and asset portfolios, and social networks. Especially important in this context is the role of institutions. They affect the impacts of climate-related phenomena, shape the access of individuals and groups to assets and services, and allocate available and external resources by structuring impacts of actions and decisions.

A comparative study of two districts in India strikingly illustrates how local institutional, policy, and micro-ecological variations affect access to resources, levels of vulnerability, and ability to adapt (see box 1).

\section{Box 1: Climate Impact Variations in Semi-Arid Regions and the Role of Institutions}

Anantapur district in Andhra Pradesh India is a drought-prone area exposed to climate change as well as economic liberalization impacts. Growing import competition and stagnant market prices have coincided with a multi-year drought to threaten the principal crop in the district: groundnut. It is difficult for farmers to switch livelihoods. Rain-fed fruit crop varieties require too much capital, and have too short a shelf life to be marketable. Dry-land farmers find themselves in a highly vulnerable position.

In contrast, groundnut farmers in the neighboring district of Chitradurga in Karnataka exhibit lower levels of vulnerability owing to lower climate sensitivity and higher adaptive capacity. They are vulnerable to trade liberalization, but many have taken advantage of available irrigation and state government policies to cultivate alternative crops such as arecanut, pomegranate, and banana. Larger farmers have benefited especially from subsidized drip irrigation, cheap bank credit, crop insurance, and contracts with export 
companies for gherkin production aimed at European markets. Smaller farmers lack information and depend on local merchants for credit.

The comparison shows the crucial role of institutional barriers vs. support systems. In Anantapur, institutional barriers leave farmers poorly equipped to adapt to climatic and economic stresses. In Chitradurga, institutional support facilitates adaptation to both climatic change and trade liberalization. And such support benefits larger farmers disproportionately. As Brooks et al. (2005: 152-53) note, vulnerability depends critically on context, and is a function of both the hazard and the system in question.

(Source: O'Brien et al. 2004)

\section{Climate Impacts and Types of Adaptation}

Two recent major surveys of climate change and its impacts have identified many areas in which there is now significant scientific consensus about the significant adverse impacts of climate change on agricultural, food, water, social, and ecological systems (IPCC 2007a, 2007b, Stern 2006). There also now exists a well developed body of work around the key concepts of vulnerability, resilience, and adaptation in the context of global environmental change (Janssen et al. 2006). This evidence suggest that climate change will stress existing livelihood options, and even more importantly, make them more unpredictable owing to increased volatility in climate impacts (Rosenzweig and Parry 1994, Pimental 1999, Wandiga et al. 2006, Yohe and Tol 2002).

The problem of increased volatility and risks owing to climate change is especially important. It means that many more vulnerable households can periodically be driven into destitution and hunger and find it difficult afterwards to recover. This is because the incomes and livelihoods of poorer, more vulnerable households, by definition, are closer to the line separating an adequate subsistence from malnutrition and starvation. When variations in climate impacts and consequently in livelihoods increase, it is logically obvious that poorer households will more frequently face declines below subsistence levels. They will need to identify and rely on livelihoods sources that allow them therefore either to smooth consumption to survive through periods of scarcity, or to maintain livelihoods such that they do not dip below subsistence levels.

The role of rural local institutions in this regard is critical. Not only do institutions affect how households are affected by climate impacts, they also shape the ability of households to respond to climate impacts and pursue different adaptation practices, and mediate the flow of external interventions in the context of adaptation. The nature of access of different households and social groups to institutions and institutionally allocated resources is a critical factor in their ability to adapt successfully.

It is clear therefore that development strategies and institutional interventions that focus simply or even mostly on improving total benefits to poor households without taking into account how households can address fluctuations in their livelihoods are ill-suited to address the impacts of climate change. They are ill suited for two reasons. On the one hand, they ignore a critical feature of climate-related stresses increased riskiness of livelihoods because of the nature of impacts climate change is likely to generate. Relatedly, they ignore the very real concerns of the rural poor about preventing starvation and destitution. Indeed, a long tradition of scholarship in the social sciences has argued about the extent to which many rural households live close to the margins of subsistence (Scott 1976, Wolf 1969), and seek to avoid drops in livelihoods below subsistence (for a discussion of the links between climate risks and household level livelihoods outcomes, see Rasmus et al. 2008).

There is significant consensus in the literature about the generally adverse impacts of climate change on rural populations, and the hazards through which such impacts will become manifest. Some of this consensus is reflected in the overlap between the different kinds of indicators used to assess vulnerability (see table 1). At the same time, we also face uncertainties in how particular locations and groups will experience and be affected by climate change. Policy interventions can therefore more fruitfully focus on improvements in adaptive capacity of disadvantaged rural populations rather than on identifying specifically how a given group of rural poor in a particular area will be affected by climate change. Efforts to reduce vulnerability and enhance adaptive capacity of at-risk-groups need to attend especially to proactive approaches that address social processes leading rural poor into vulnerable conditions, and structural inequalities that are often at the root of social-environmental vulnerabilities (Thomkins et al. under review).

Table 1: Key Indicators of Vulnerability at Different Levels (Adger 1999, Brooks et al. 2005, Eakin 2005) 


\begin{tabular}{|c|c|c|}
\hline $\begin{array}{l}\text { National/Regional Level } \\
\text { (Indicators) }\end{array}$ & Community Level (Variables) & Household Level (Variables) \\
\hline $\begin{array}{l}\text { 1. population with access to } \\
\text { sanitation, } \\
\text { 2. literacy rate, } 15-24 \text {-year olds, } \\
\text { 3. maternal mortality, } \\
\text { 4. literacy rate, over } 15 \text { years, } \\
\text { 5. calorific intake, } \\
\text { 6. voice and accountability, } \\
\text { 7. civil liberties, } \\
\text { 8. political rights, } \\
\text { 9. government effectiveness, } \\
\text { 10. literacy ratio (female to } \\
\text { male), } \\
\text { 11. life expectancy at birth. }\end{array}$ & $\begin{array}{l}\text { 1. poverty } \\
\text { 2. inequality } \\
\text { 3.social capital } \\
\text { 4. social entrepreneurs } \\
\text { 5. institutional interconnections } \\
\text { 6. institutional density } \\
\text { 7. institutional effectiveness } \\
\text { 8. gender composition } \\
\text { 9. cultural factors (whether } \\
\text { indigenous) } \\
\text { 10. age compositions }\end{array}$ & $\begin{array}{l}\text { 1. poverty } \\
\text { 2. dependence on risky resources } \\
\text { 3. asset portfolios } \\
\text { 4. occupations } \\
\text { 5. skill sets } \\
\text { 6. information availability } \\
\text { 7. labor availability } \\
\text { 8. institutional access } \\
\text { 9. literacy } \\
\text { 10. gender balance } \\
\text { 11. age distribution }\end{array}$ \\
\hline
\end{tabular}

The above table draws attention to three aspects of social and household level vulnerability. In identifying factors such as age composition, gender, and culture as influencing community level vulnerability, it suggests that many of the structural obstacles to development identified by scholars of development are also equally important in thinking about vulnerability to climate change. It is very likely that women, indigenous populations, the very young or the very old, and the poor will suffer more from the effects of climate change. Second, vulnerability is a function not just of the nature and strength of environmental impacts, but also of variations in socio-economic factors. Finally, although there are clearly developed measures of some variables that affect vulnerability, such measures still remain to be generated for others.

Indicators of vulnerability and their specific measures are an initial step in the direction of assessing the extent to which different territories and actors within them will be affected by climate change, and the kinds of adaptation interventions necessary to safeguard their livelihoods. The list of indicators above shows the importance of a wide range of non-climatic variables in shaping the extent to which rural households and communities are susceptible to different environmental risks and the role of institutional linkages, governance factors, and access to different kinds of assets in this regard.

\subsection{Historical Experiences of Environmental Risks and Vulnerability}

To strengthen the adaptive capacity of the rural poor, therefore, governments and other external actors need to understand, take advantage of, and strengthen already existing strategies that many households and social groups use singly or collectively. In different parts of the world, many rural communities already experience high levels of climate variability and have developed more or less effective responses to address such variability. Much of the Sahelian region, for example, faces extreme irregularity in rainfall with recurrent droughts. A number of scholars have argued, based on available data, that annual rainfall levels in the region have declined together with an increase in inter-annual and spatial variability as well as the intensity of drought events (Hulme et al, 2001, Tarhule and Lamb 2003). In response, farmers have adapted their farming, livestock rearing, and other income generating activities to achieve some degree of sustainability in their livelihoods (Blanco 2006, Nyong et al. 2007). Similar arguments can also be found about the way climate change is already affecting rural landscapes and livelihoods (Howden et al. 2007, Zheng et al. 2006).

\section{2: Classes of Adaptation Practices and their Characteristics}

A policy-relevant framework for examining adaptation practices in the context of rural institutions and livelihoods needs to be sufficiently general to cover the many empirical examples of adaptation practices used by different social groups, but also needs to be based on an analytical approach that takes into account the most important characteristics of the impacts of climate change on rural livelihoods likely increases in environmental risks, reduction in livelihoods opportunities, and stresses on existing social institutions.

Increases in environmental risks as a result of climate change can be classified in many ways: short term vs. long term, those resulting from sudden disasters vs those resulting from slow but secular 
changes in trends, predictable vs unpredictable, and the like. In looking at household livelihoods strategies particularly useful way to think about climate-related risks is to examine how they affect livelihoods capabilities over time, across space, across asset classes, and across households.

The basic coping strategies in the context of environmental risks to livelihoods can then be classified into five analytical categories of adaptation responses and their combinations: mobility, which helps address risks across space, storage (time), diversification (asset classes), communal pooling (across households), and market exchange - which can substitute for the above four classes of risk mitigation when households and communities have access to markets (Halstead and O'Shea1989 discuss four of these). The effectiveness of these strategies is in part a function of the social and institutional contexts in which they are pursued. Where successful, these responses pool uncorrelated risks associated with flows of benefits from different classes of assets.

Mobility is perhaps the most common and seemingly natural responses to environmental risks. It pools risks across space, and is especially successful in combination with clear information about the spatial and temporal distribution of precipitation. It is especially important as an adaptation strategy for agropastoralists in Sub-Saharan Africa, west and south Asia, and indeed most dry regions of the world (Niamir-Fuller 1999).

In the context of climate change mobility has sometimes been viewed as a maladaptation, in which climatic stresses lead to involuntary migrations on a massive scale with attendant social and political instabilities (Tickell 1990). However, mobility is also a way of life for large groups of people in semi-arid regions, and a long standing mechanism to deal with spatio-temporal variations in rainfall and range productivity. Mobility as an adaptation practice, therefore, is more or less desirable depending on the social groups being considered.

For agricultural populations, mobility can often be the last resort in the face of environmental risks and disruption of livelihoods (McGregor 1994). For pastoralist and agro-pastoralist populations, on the other hand, efforts to limit mobility could lead to greater vulnerability and lower adaptive capacity (Agrawal 1999, Davies and Bennett 2007). At the same time, frequent movement of people with their animals raise particularly intricate questions about the role of institutions in facilitating adaptation. Most governance institutions are designed with sedentary populations as their target. To address the needs of mobile populations, the role of information in tracking human and livestock movements, and mobile provision of basic services such as health, education, credit, and marketing of animal products is especially important to reinforce adaptive capacity.

Storage pools and reduces risks across time. When combined with well constructed infrastructure, low levels of perishability, and high level of coordination across households and social groups, it is an effective measure against even complete livelihood failures at a given point in time. As an adaptation practice to address risks, storage is relevant to individual farmers and communities, and to address food as well as water scarcities. Indeed, in light of the significant losses of food and other perishable commodities all over the developing world, improvements in storage technologies and institutions have immense potential to improve rural livelihoods.

Diversification pools risks across assets and resources of households and collectives. Highly varied in form, it can occur in relation to productive and non-productive assets, consumption strategies, and employment opportunities. It is reliable to the extent benefit flows from assets are subject to uncorrelated risks (Behnke et al. 1993, Ellis 2000, Sandford 1983). Diversifying households typically give up some returns in exchange for the greater security provided by diversification. Davies and Bennett (2007) provide a striking example from the Afar pastoralists of Ethiopia where many of them would be willing to live with some level of poverty in exchange for reduction in vulnerability. More typical forms of diversification are those reported by Young and Lipton (2006) for the Quechua in Peru (see box 2).

\footnotetext{
Box 2: Diversification of Assets and Occupations among the Quechua in Peru

Quechua households living near the Huascaran National Park in north-central Peru have reported seeing significant changes in climate within their lifetimes. Impacts of these changes include retreat of glaciers, greater variability as well as decline in precipitation, and for some, associated declines in agro-pastoral productivity. As a result many households report extensive diversification. Within the agricultural sector, farmers have adopted new maize varieties. Some have also moved away from agro-pastoralism, typically by resorting to wage labor in tourism and mining economies and in government construction projects. Local residents also report seeking improvements in their skills and technical capacities.

Local residents report widespread distrust of government and other external institutions, especially those
} 
associated with environmental conservation. Community institutions, in contrast, are viewed as providing reliable scaffolding in times of need and risks by providing support, information, and expertise.

(Source: Young and Lipton 2006)

Communal pooling refers to adaptation responses involving joint ownership of assets and resources; sharing of wealth, labor, or incomes from particular activities across households, or mobilization and use of resources that are held collectively during times of scarcity. It pools risks across households. It is most effective when the benefits from assets owned by different households and livelihoods benefit streams are uncorrelated. When a group is affected in a similar manner by adverse climate hazards - eg, floods or drought, communal pooling is less likely to be an effective response.

Although communal pooling can occur in combination with the other three ways of addressing environmental risks mentioned above, its hallmark is joint action by members of a group with the objective of pooling their risks and resources. Joint action on the one hand increases the range of impacts in comparison to that with which households could have coped individually. It also requires functioning and viable institutions for coordination of activities across households. It is one way for social groups, especially those dependent on natural resources for livelihoods, to enhance their capacity to adapt to the impacts of future climate change as advocated by Tompkins and Adger (2004). Indeed, the example they provide illustrates the above points well. Collective action through community-based coastal management in Trinidad and Tobago helped enhance adaptive capacity in two ways: by building networks important to cope with extreme events and by ensuring the resilience of existing resources and ecological systems.

\section{Box 3: Communal Pooling for Coastal Management in Trinidad and Tobago \\ Coastal management in Trinidad and Tobago is particularly controversial, as it is in many island states and other tropical coastal areas. Controversies arise because of competing demands related to conservation and development. With impending climate change, existing conflicts are likely to become more intense. In the Buccoo reef area of Tobago, institutions prior to the 1990s were relatively exclusionary, and conflicts between development and environmental imperatives proved difficult to resolve. \\ Action research in 1997-2000 was followed by a process of deliberation and learning in which various stakeholder groups came together for discussion, engagement, data collection, and information sharing so as to develop effective strategies to reverse ongoing environmental deterioration. The creation of an informal group led to greater communication and small behavioral modifications such as more careful use of oil in boats to reduce spillage, launching of an information campaign, and increased community outreach. \\ Joint action also led to greater leverage in interactions with government officials and agencies. At the same time, government officials found the group an effective partner in introducing changes in coastal management practices. This case highlights the importance of inclusionary communication and deliberation, institutionalized mechanisms for social learning, and communication and resource flows that connect local and external actors. These developments have increased community level resilience and helped local groups address risks of climate change flexibly. \\ (Source: Tompkins and Adger 2004).}

Exchange is perhaps the most versatile of adaptation responses. Indeed, markets and exchanges are a characteristic of almost all human groups, and are a mechanism not just for adaptation to environmental risks but also critical for specialization, trade, and welfare gains that result from specialization and trade at multiple scales. Exchange-based adaptation practices can substitute for the first four when rural poor have access to markets. But they are likely to do so mainly when there are well developed institutions to facilitate market access. Further, equity in adaptation practices based on market exchanges typically requires great attention to the institutional means through which access to markets and market products becomes available to households. In the absence of institutional mechanisms that can ensure equity, the rural poor are less likely to benefit from purely market exchange based adaptation. A prominent example of market-based adaptation to climate change is weather-related insurance schemes designed for agricultural or pastoralist populations (see box 4).

\section{Box 4: Livestock Insurance in Mongolia and Climate Change Risks}

Market oriented insurance instruments offer significant capacity to manage and spread risks associated with weather-related events. They are far more widespread in the industrialized world as the figure below 


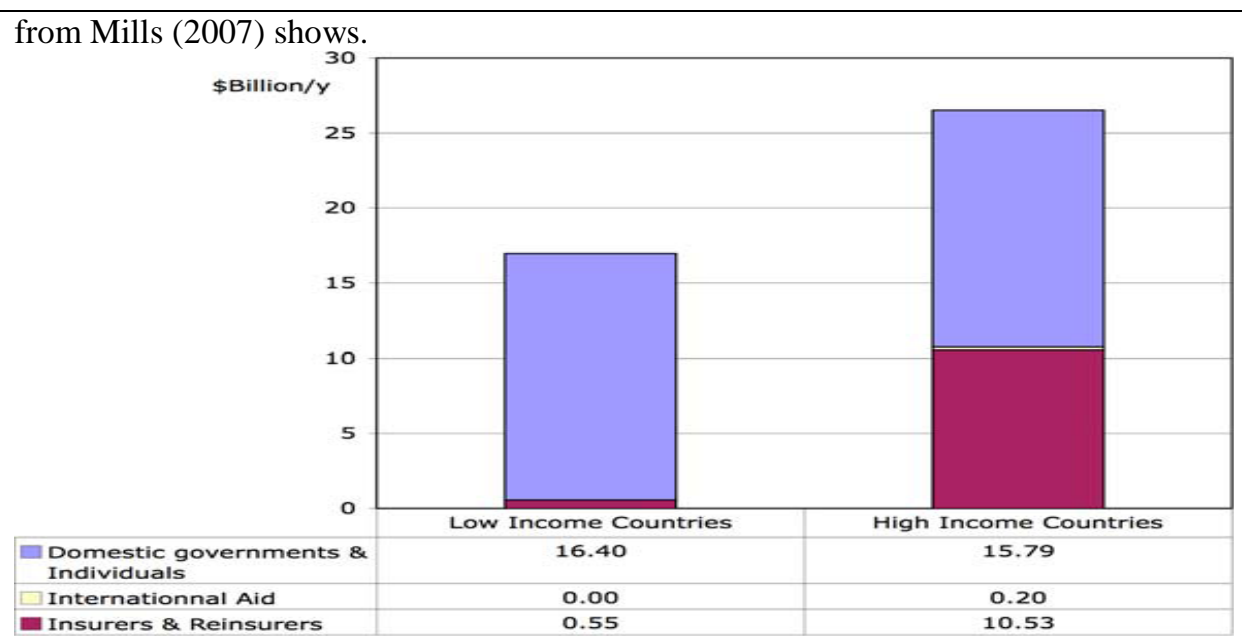

But their role is likely to assume increasing importance in developing and transitional economies as well. Promising strategies involve products and systems that reduce vulnerability to disaster-related losses and support sustainable development. Even as climate change erodes the insurability of some risks, proactive insurance responses with complementary roles by donors, governments, and local communities can address the needs of highly vulnerable groups and populations, especially those depending on occupations directly affected by weather related fluctuations. Implementing such insurance contracts will require the development of measurable and verifiable criteria for assessing whether adaptive livelihoods practices have been adopted, and more generally will need mechanisms that reduce moral hazard.

The World Bank-supported pilot Index-Based Livestock Insurance Project in Mongolia, resulting from a nationwide participatory poverty assessment and a Bank-supported Sustainable Livelihoods Program is one such initiative (Mearns 2004). Currently under implementation, the project addresses the weather-related risks faced by Mongolian herders. Weather-related losses to pastoralists have been significant in recent years; traditional insurance products have proved to be too costly because of correlated risks. The proposed insurance scheme layers the risks faced by pastoralists through a base insurance product that is based on total animal mortality in a given location and is offered by commercial insurers, and a disaster relief product which provides relief to registered herders when collective losses reach catastrophic levels. A small proportion of risk is borne by herders themselves.

The innovative aspects of the IBLI concern the effort to overcome several traditional obstacles to the success of insurance products in agricultural contexts. Small size of individual contracts is dealt with through a product available to all registered herders; indexing payments to catastrophic collective losses helps mitigate against adverse selection and moral hazard. Using market-based insurance to address climate risks will require similar partnerships between public, private, and community actors.

(Source: Mills 2007 and World Bank 2005).

\subsection{Determinants of Adaptation Practices}

The choice of specific adaptation practices is dependent on social and economic endowments of households and communities, and their ecological location, networks of social and institutional relationships, institutional articulation and access, and access to resources and power. For example, the poor are more likely to migrate in response to crop failure; the rich more likely to rely on storage and exchange. This is because the rich are more likely to have institutionally secure access to resources that make forced migration unnecessary. Migration is more likely to be an effective long-term strategy for pastoralists and agropastoralists confronting lower rainfall or range productivity in contrast to settled agriculturists. But the ability to migrate depends on the nature of property institutions over pasture lands along the migration route. Occupational diversification into agricultural activities may reduce the long-term adaptive capacity of pastoralist groups in contrast to diversification into part time wage employment or even investment in market exchanges during times of rainfall stress. But such diversification may be impossible if access to agricultural land is unavailable.

Similarly, whether households and communities can diversify into new occupations and assets depends on the extent to which they have the ability to trade some level of returns for lowered risks, but it 
also on access to capital, availability of skills training, and the effectiveness of agricultural extension institutions. The importance of institutions as the scaffolding on which households and individuals can coordinate their expectations and thereby create effective collective action has been repeatedly demonstrated. And market exchanges depend crucially on institutions that can reduce or eliminate problems of adverse selection, moral hazard, and in general lower different types of transactions costs.

In addition, the different adaptation practices above have natural affinities and incompatibilities. Storage and mobility tend not to go together. Other combinations complement each other: storage and exchange can play off temporal variability against spatial variability (Halstead and O'Shea 1989: 4). Diversification similarly allows agricultural households simultaneously to reduce risks, and reap the benefits of market exchange.

The five classes of adaptation practices contain wide variations in terms of specific adaptation actions they each cover. To assess their suitability for specific social groups, it is necessary to understand better the characteristics of the groups and their contexts (see section 6).

\section{Rural Local Institutions and Adaptation to Climate Change}

In examining the role of rural institutions in adaptation, it is necessary to pay attention to three sets of factors: their nature and goals, patterns in how specific types of institutions facilitate particular types of adaptation strategies, and their linkages with each other and with different rural households. An understanding of the above three aspects helps identify the characteristic features of institutions relevant to successful adaptation outcomes. The paper focuses on the types of institutions by appealing to the familiar distinction between public, private, and civil society institutions. It suggests that they play three general roles in relation to climate variability and change: structuring risks and impacts, acting as links between individual and collective actions, and mediating external interventions. Finally, it examines linkages among institutions through social network analysis tools for institutional mapping.

Although households and communities have historically adapted to climate variability through many different strategies, their capacity to adapt depends in significant measures on the ways institutions regulate and structure their interactions: both amongst themselves and with external actors. All adaptation practices discussed in section 3 depend for their success on specific institutional arrangements -- adaptation never occurs in an institutional vacuum. They all, thus, depend on clear property rights and other institutions that regulate access to resources and exposure to risks. Storage requires physical infrastructure, but it also depends on institutionalized monitoring and sanctioning in case of individual or collective infractions of rules governing storage. Mobility can take place only with adequate information about the spatial and temporal structure of variability in precipitation and range productivity. No wonder many indigenous pastoralist systems developed strong norms of information storage and exchange (Agrawal 1999, Nyong et al. 2007).

Indeed, the role of institutions at multiple scales, including local contexts, is broadly accepted in many analyses of climate and adaptation (Batterbury and Forsyth 1999, Thompson et al. 2006, Young and Lipton 2006). Specific studies focusing on themes such as water conservation, agricultural development, rural livelihoods, forest governance (Adger 200b, Droogers 2004, Naess 2005, Shepherd et al. 2006, Ziervogel 2003) have all identified local institutions as being key to adaptation. And yet, relatively little of the existing work has undertaken a careful or systematic analysis of the different types of institutions relevant to climate hazards-related adaptation, the different roles of local institutions in the context of adaptation, or the features of institutions most important for successful adaptation in rural contexts in the developing world (but see Bakker 1999, Tompkins and Adger 2004).

Local institutions are obviously critical to adaptation. The relative absence of systematic, comparative work to enable targeted policy initiatives that can strengthen local institutions and enhance adaptive capacity is therefore all the more striking. Undertaking such an analysis would require significant empirically based research on a selected, comparable set of adaptation projects. However, it is still possible to identify a basic institutional typology relevant to local adaptation efforts, the types of roles local institutions perform in relation to the broad classes of adaptation strategies identified in section three, and begin to focus on some of the factors presented in the institutional literature as leading to improved institutional performance. This section makes an initial attempt along these three directions.

\subsection{Classifying Local Institutions Relevant to Adaptation}

In examining the role of local institutions in facilitating adaptation, this paper focuses on three types of institutions: civic, public, and private, primarily in their formal but where relevant, also informal 
form. Certainly, it is possible to categorize local institutions in a variety of ways as the institutional literature has demonstrated. The differences among the various attempts to classify institutions hinge ultimately on the aspects or features of institutions considered most relevant to institutional design and performance. Analytical approaches thus have focused, among other dimensions, on the degree to which rural institutions are formal or informal, whether they are sector-specific or multi-sectoral/general purpose, and on their hierarchical nature (IFAD 2003). In this paper, the analytical focus is on the three broad domains of social action - market/private, public/government, and civic/community - to cover the range of institutions relevant to adaptation to climate change and addressing the different forms of vulnerability that the rural poor are likely to suffer as a result of climate variability and change.

Within these three broad domains, it is possible to recognize additional relevant distinctions. Focusing mainly on organizations because of their formal and concrete nature, Uphoff and Buck 2006 highlight two important types of local public institutions: local governments (organizations accountable to a local constituency through elections or some other mechanisms) and local agencies (agencies or arms of higher levels of government operating at local levels). They similarly identify two types of civic institutions (membership organizations that function in a manner analogous to companies and advance some common interest of their members; and cooperatives which function more like partnership and help members pool resources for improved economic outcomes), and two types of private institutions (service organizations including such as NGOs and charities and private businesses). Their typology is summarized below in table 2.

Table 2: A proposed typology of local rural organizations

\begin{tabular}{|l|l|l|l|}
\hline & Public (state) & Private (market) & Civic (civil society) \\
\hline Types of institutions & $\begin{array}{l}\text { Local agencies } \\
\text { Local governments }\end{array}$ & $\begin{array}{l}\text { Service organizations } \\
\text { Private businesses }\end{array}$ & $\begin{array}{l}\text { Membership } \\
\text { organizations, } \\
\text { cooperatives }\end{array}$ \\
\hline
\end{tabular}

It is worth pointing out that in many contexts, formal local institutions and organizations work in ways that promote informal processes, and these interactions can be critical to adaptation. Further, although the analytical distinctions among these different types of organizations are important to bear in mind, in their functioning these organizations often enter into partner relationships, promoting cross-domain collaborations.

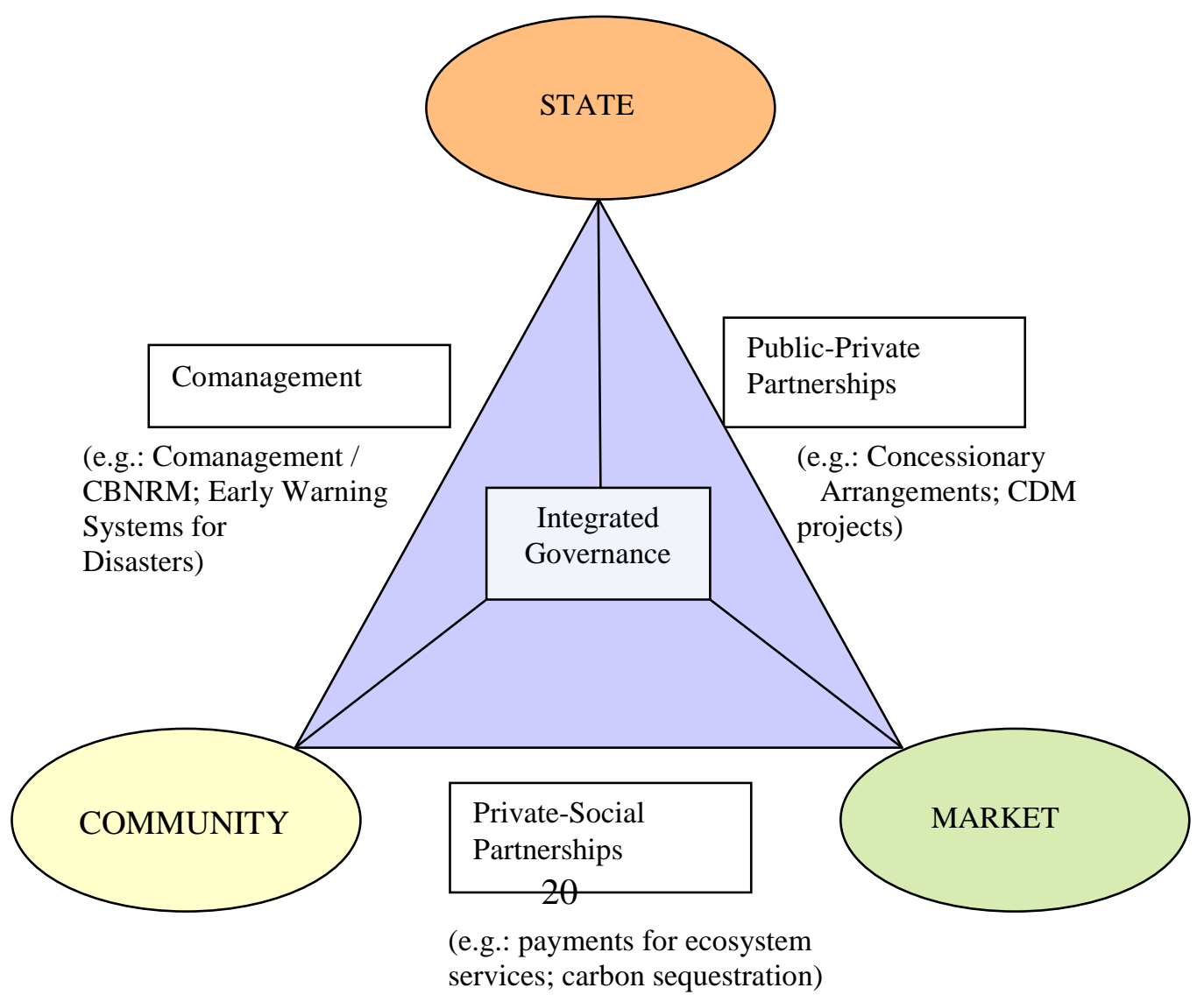


Figure 3: A Schema of Collaborative Institutional Arrangements for Environmental Action in the Context of Climate Change (Agrawal and Lemos 2006)

Indeed, there are strong reasons to believe that such partnerships between public, civic, and private organizations can prove extremely important in addressing climate hazards related adaptation. Figure 3 above proposes a schematic representation of such partnerships and collaborative arrangements as a first step in analyzing how institutions across the public, civic, and private boundaries can work jointly to help facilitate adaptation.

The basic motivation for such collaborative arrangements stems from the specific limitations of institutions and organizations within the private, public, or civic domains. With their main focus on regulating socioeconomic interactions (public), promoting voluntary/social relationships (civil society), or generating profits (market), organizations within these three domains may not have sufficient capacity or expertise to facilitate adaptation which, depending upon the context, may require the pursuit of a mix of objectives through flexible operational strategies. But in collaboration, each type of organization may be able to overcome the weaknesses of its partners. The success of such partnerships obviously depends significantly on common or complementary perceptions about the problem to be addressed, and coordination of organizational strategies to achieve adaptation-related goals.

Such partnerships have become especially common in the environmental arena as well as in the context of development projects. In many instances, government agencies have sought to manage resources more effectively by partnering with civic bodies, reduce pollution by working with corporations, implement development projects in partnership with NGOs, or decentralize control over administrative functions and outsource important functions related to accounting, record keeping, financial management, and project monitoring and evaluation.

The figure above thus not only suggests the possibility of institutional partnerships across the public-private-civic domains in the context of climate adaptation, it also highlights the importance of such partnerships. A number of people have called climate change one of the greatest market failures of human history. It is clear that adaptation to climate change will require the concerted efforts of decision makers in diverse institutions across multiple scales.

\subsection{How do Local Institutions and Organizations affect Adaptation and Livelihoods?}

Broadly speaking, different local institutions shape the effect of climate hazards on livelihoods in three important ways.

They structure environmental risks and variability and thereby the nature of climate impacts and vulnerability. Depending on the nature of governance and institutional configurations, the same phenomenon - say, reduced precipitation in a region by $20 \%$ in a given year - will have very different effects on the livelihoods of residents in the region. More equitable access to livelihoods-related institutions and their resources, coupled with transparent communication and governance is likely to reduce the ill effects of rainfall failure in contrast to a situation where institutional access is highly stratified and information about institutional capacities is monopolized by a small group.

Institutions create the incentive framework within which outcomes of individual and collective action unfold. It is within such incentive frameworks that households and collectives choose specific upon adaptation practices. Strong institutional norms around labor sharing may, thus, reduce the ability of households to migrate or diversify. Closer social networks may make it easier to undertake communal pooling of resources as illustrated in box 3 above about the Tobago case.

Institutions are the media through which external interventions reinforce or undermine existing adaptation practices. In this context, greater attention to the reasons why households and collectives opt for one type of adaptation practice vs. another is necessary if external interventions are to reinforce the adaptive capacity of the rural poor. Social groups that do not have secure rights to land will find it more difficult to diversify asset portfolios or engage in exchange as illustrated by the example in Box 4. Lacking access to capital and infrastructure, groups may be unable to use either storage or exchange to address environmental risks. Without access to markets, communities may be forced to pursue ways of storing their harvest carefully and invest resources into storage infrastructure. It is especially important to attend to these 
empirical patterns because reliance on particular adaptation practices can have lasting implications for the extent to which the rural poor can adapt either successfully or sustainably to future risks (see box 5).

\section{Box 5: \\ How Institutions Structure Climate Impacts, Adaptation Choices, and Outcomes}

Households' management of climatic risk is a function of education, wealth, natural resources, social organization, local knowledge, and institutional relationships among other factors (see, e.g., Brush, 1977; Mortimore, 1989; Netting, 1993; Zimmerer, 1991). In examining the responses of households from three different communities in Mexico, Eakin found that a wide range of adaptive responses to climate variability and change. In one community, households engaged in a more diverse set of productive activities, intensified their involvement in non-farm work including public works programs, and emergency food distribution campaigns. In a second community, household primarily engaged in migration and selling livestock to buy maize. And in a third, extensive labor demands and high investments in irrigated agriculture led many households to accept the migration of some members to the United States.

These differences in household responses across the three communities are indicative of resource endowments but also of institutional support at the local level, and market integration and institutional linkages at higher levels. Depending on institutional access to land, markets, and social networks, households intensify agricultural production, diversify into livestock or new crops and engage in market exchanges, or invest in education and migration to manage changing patterns of climate and other risks. Institutional connections provide households and communities greater flexibility in their choice of diversification and adaptation strategies.

This case also points to the difficulties inherent in attempting to gain a generalized picture of vulnerability and adaptive capacity based on a list of indicators and quantitative measurements (but see Brooks et al. 2005: 157). As much as the presence of formal and informal institutions, it is their linkages with each other and rural households that affects how climate change and variability produce their effects. (Source: Eakin 2005).

As the case description in box 5 for three communities in Mexico illustrates, local institutions play a crucial role in influencing the adaptive capacity of communities ex ante, and the adaptation choices made by community members ex post. The above example also shows the importance of close connections between local and higher level institutions, and the extent to which such connections allow rural residents to leverage their membership in local institutions for gains from outside the locality. Indeed, the critical role of institutions is underscored in study after study of adaptive capacity and adaptation choices (Adger 1999, 2000b, Berkes and Jolly 2001, Ivey et al. 2004).

Local institutions structure livelihoods impacts of climate hazards through a range of indispensable functions they perform in rural contexts. Institutional functions include information gathering and dissemination, resource mobilization and allocation, skills development and capacity building, providing leadership, and relating to other decision makers and institutions. Each of these functions can be disaggregated further, but the extent to which any given institution performs the above functions depends greatly on the objectives with which the institution was formed, and the problems it has come to address over the course of its existence (see box 6).

\footnotetext{
Box 6: Local Institutions and Soil Conservation in Tanzania

The Shinyanga region in northern Tanzania is occupied mainly by the agropastoral Sukuma people. The Hifadhi Ardhi Shinyanga (HASHI) project, which means "soil conservation" in Kiswahili, is a government initiative under the Ministry of Natural Resources and Tourism and is implemented by a local agency of the ministry. The project works closely with traditional institutions at the local level, and has had a key role in reviving the Sukuma people's traditional conservation practices. Using indigenous knowledge, they practice a natural resource management system called ngitili - a Sukuma word meaning enclosure. Traditionally ngitilis were used to provide fodder for very young, old or sick animals unable to move to grazing lands. Through planting activities and community involvement, ngitili today provides livelihoods resources for communities in the region when environmental conditions deteriorate.

The Shinyanga region used to be extensively forested with dense woodland and bushland species. Earlier relocation schemes launched by the Tanzanian state - together with drought, over-grazing, cash crop cultivation, destruction of forests to wipe out tsetse fly and increased demand for firewood - reduced productivity and increased soil erosion. The Shinyanga landscape is now changing, thanks to farmers'
} 
enthusiasm for agroforestry and careful consideration of site suitability, use of degraded croplands and rangelands, demarcation and issuing of deeds, employment of traditional village guards, and conservation by closing off ngitilis for regeneration.

This case illustrates the different functions performed by local institutions: information exchange, coordination among groups, planning for and mobilizing resources, providing leadership, improving production, distributing output - all aimed at improving livelihoods and coping with environmental hazards. Without such organizations, outcomes would be costlier, uncoordinated, and potentially negative.

Source: UNFCCC Coping strategies database

4.3: Institutional Linkages: Access and Articulation

The capacity of particular institutions is obviously important in how they affect adaptation. But equally important are the interconnections of institutions in a given location. Institutional linkages are critical to adaptation because of the ways in which institutional linkages affect flow of resources and influence amongst themselves and to households and social groups.

Institutional linkages can be of two types. One type of linkages can be defined as institutional access. Households and social groups in a given territory or village have different degrees and types of links with the institutions in that location. Some households may participate in the meetings, day-to-day functioning, and decision making of a rural institution. Other households may be unconnected. Some households may benefit as a result of their connections or of institutional policies, Other households may be left untouched. Some households may work to shape what an institution does. Others may try and fail, or not even try. The degree and type of access of households to different institutions will affect the nature of benefits they gain from these institutions.

Another type of institutional linkage refers to those that institutions have with each other. These linkages can be called institutional articulation. Even if there are multiple rural institutions in a given location, the nature of their impacts on adaptation will be very different depending on the degree to which they are connected, whether and how they coordinate their actions and responses to climate hazards, and how they articulate with institutions and resources outside their immediate area of operation. Institutions without any links to other institutions - usually an empirical impossibility - or with conflictual links to other institutions are likely to be far less effective than those with multiple positive links with other institutions.

The importance of institutional articulation has already been implicitly indicated in figure 3 which points to comanagement, public-private partnerships, and private-social partnerships as being potentially highly relevant to adaptation to climate change. But given the importance of institutional linkages, it is crucial to use analytical tools that can help identify, visualize, and analyze institutional access and articulation (see box 7). Social network analysis provides useful tools for this purpose.

A better understanding of institutional linkages - both access and articulation - is essential to gain a grasp on how local rural institutions are likely to shape adaptation practices and responses in any given context. Such mapping provides a sense of the possible synergies among existing institutions, key entry points for external interventions, identity of key institutions and their capacities, the nature of flow of resources across institutions and from institutions to social groups, and thereby identify the appropriate leverage points for channeling resources for adaptive development in a given context. In contrast, much existing institutional analysis rarely attends to the nature of links among institutions and social groups, instead focusing upon specific institutions and their individual capacity.

\section{Box 7: Institutional Access and Articulation}

Social network analysis is a useful tool to understand and visualize institutional access and articulation. The figure below provides a simplified hypothetical example of how social network analysis can be used to present information about institutional access of different social groups, and institutional articulation among different institutions in a location.

The figure selects three local institutions and their links to two social groups for visual presentation. In the figure, institutions and groups are represented as nodes, and their links as ties. It shows the strength and direction of the links among institutions (through arrowheads and thickness of the connecting lines). Credit groups have a strong link with irrigation institutions, but the link between labor groups and irrigation institutions is weaker. It also shows the relative capacity of the different institutions and groups through the size of the nodes. 


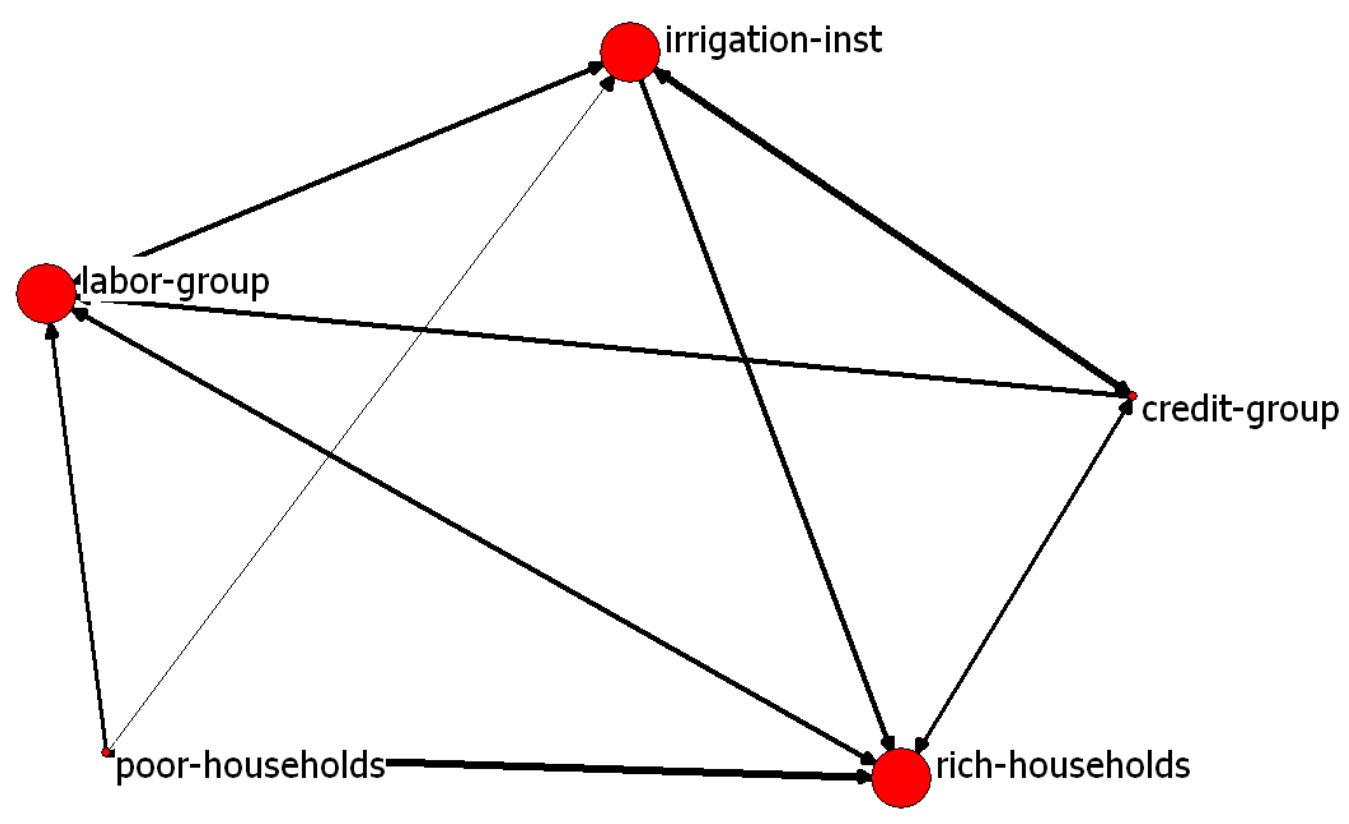

A simplified illustrative mapping of institutional access and articulation

Finally, the figure also shows the nature of institutional access for rich vs. poor households. Rich households have greater access to the different institutions in this location, and their links tend to be stronger in comparison to the access of poorer households. The arrows pointing to rich households indicate that the flow of benefits from institutions is more toward them than is the case for poor households. Although it only provides a static picture, the figure suggests that external interventions in this context through the existing institutions have a strong likelihood of benefiting primarily the rich households who already have strong access to these institutions.

\section{4: Features of Effective Local Institutions for Climate Adaptation}

The critical role of local institutions in facilitating adaptation to climate change is evident. Nonetheless, little of the existing literature on the subject has attempted to identify the general factors relevant to better institutional performance. In attempting to identify some of the factors that likely promote superior performance on the part of local institutions, two sets of writings on community institutions for resource governance, and on decentralization of governance more generally are useful to consider. Many of the local institutions that promote adaptation and help improve livelihoods do so through better and more sustainable governance of local resources. A significant literature on common pool resources provides some insights into the kinds of factors that might help improve livelihoods outcomes. Two, because our concern is with local, decentralized institutions, existing writings on decentralization and local governance are also relevant to understand when institutions may work better.

Writings on the commons have provided perhaps the most systematic account of the factors that help promote better governance. The main conclusion of this body of work is that factors related to the context as well as to institutional design are relevant to institutional performance. In assessing contextual factors, it is important to pay attention to socio-economic, demographic, ecological, as well as political factors. In considering institutional factors, it is necessary to attend to the operational as well as higher level decision processes. The literature on decentralization provides important insights into the ways effective local institutions relate to external, higher level decision making bodies and organizations. Box 8 provides a summary set of the relevant factors identified in these two literatures as relevant to effective local institutions.

\section{Box 8: Factors Promoting Better Institutional Performance for Adaptation}




\section{Characteristics of Institutions}

-- Organizational rules are simple and easy to understand

-- Broad local involvement in organization and its rules

-- Fairness in resource allocation

-- Clear mechanisms for enforcing rules

-- Clear, broadly acceptable mechanisms for sanctioning rule infractions

-- Availability of low cost adjudication

-- Accountability of decision makers and other officials

\section{Characteristics of the Context of Institutions}

-- Mechanisms for dissemination of new technologies and training in their use

-- Favorable returns for products sold in markets

-- Central governments facilitate the functioning of local institutions by

Creating effective support for sanctions used by local institutions

Provide necessary support in terms of information, finances, and skill development

Develop indicators of performance against which institutions can be assessed over time

-- The network of institutions present in a context and their links with different social groups

\section{Characteristics of groups served by the Institutions}

-- Clearly defined boundaries of the group

-- History of successful shared experiences; existence of social capital

-- Appropriate leadership that changes periodically- young, familiar with changing external environments,

connected to local traditional elite

-- Interdependence among group members

-- Heterogeneity of endowments among group members, homogeneity of identities and interests

\section{Characteristics of the Ecological Context}

-- Match between demands on ecological system and its output

-- Information availability about the ecological system

-- Possibility of storing benefits from the system

-- Group dependence on resources available from the ecological system

Source: Agrawal 2001, Baland and Platteau 1996, Ostrom 1990, Ribot 2002, Uphoff and Buck 2006, Wade 1994.

It is worth pointing out that the list of relevant factors in box 10 is at this point illustrative at best. It constitutes a starting point for collecting the necessary information against which to judge the performance of institutions active in facilitating adaptation.

\subsection{Bringing the Strands of the Argument Together}

The role of institutions in facilitating adaptation has already been summarized in figure 1 at the beginning of this review. At this point it is useful to recapitulate the main points, and examine some of the broad ways in which adaptive responses can be facilitated through institutions. Institutions structure adaptation in three major ways - by shaping the impacts of climate hazards on social groups and communities, and thus affecting their vulnerability and resilience; by serving as the mechanisms that link individual with collective action, and thereby the outcomes of adaptation strategies; and by acting as mediating mechanisms for external interventions.

Adaptive strategies related to climate risks can be classified along two dimensions: the timing of the adaptation, and the degree to which an adaptation practice is tied into other aspects of livelihoods of households and communities. The figure below presents the four types of adaptation strategies that can be thus identified and examples of the different combinations of these two dimensions of efforts to address climate impacts.

Figure 4: Timing and Comprehensiveness of Adaptation Strategies

\begin{tabular}{|l|l|l|}
\hline & Targeted & Integrated \\
\hline Reactive & $\begin{array}{l}\text {-- post-hazard support for recovery; } \\
\text {-- emergency coping strategies }\end{array}$ & -- integrated hazard management \\
\hline Proactive & $\begin{array}{l}\text {-- specific classes of adaptation practices; } \\
\text {-- sectoral interventions }\end{array}$ & $\begin{array}{l}\text {-- integrated development interventions; } \\
\text {-- integrated territorial development }\end{array}$ \\
\hline
\end{tabular}


Some care should be exercised in interpreting these dimensions for classifying adaptation strategies and practices. It is true that a particular practice may be adopted only after the occurrence of a particular climate hazard and thus appear to be a coping mechanism, or a post-hazard adaptation. However, because many climate hazards are recurrent phenomena, coping strategies once adopted can also appear to be proactive strategies for future, recurrent episodes of climate risks. Similarly, when considered over time, targeted interventions may come to assume more comprehensive proportions. As institutions necessary for specific climate hazard, or for a particular sector continue in time, they may accrete new tasks and functions that allow them to support adaptation practices for which they were not initially designed.

In general, however, the more forward looking an intervention, and the more comprehensive or integrated the approach, the more important it becomes to examine institutional arrangements in a given location. Such an examination is necessary not only to identify appropriate means to channel external resources and ensure that they reach intended social groups, but also to prevent duplication and conflicts among institutions. In a territorial development perspective, the mapping of institutional connections and interactions among multiple institutions are of particular importance. Insights about how policies are to be designed and implemented for delivery through institutions becomes possible in part through the examination of institutional interactions, and their relationship to the vulnerability of specific groups.

\section{External Interventions and Local Institutions}

Although the historical experiences and responses of communities and institutions to environmental risks are important to consider in crafting effective adaptation policies, it is useful to assess at somewhat greater length how institutions can facilitate external interventions designed to enhance local adaptive capacity (see box 10). Such an examination is especially important for development organizations such as the World Bank who can deploy a variety of strategies to channel external support for adaptation.

\section{Box 10: Intermediary Role of Local Institutions in Adaptation in Philippines}

In a recent survey of the types of adaptation practices in which local governments could play a role, local government actors identified more than 20 such practices in which they could play a role. These included, tree planting and reforestation, selection of appropriate crop varieties, better implementation of forest laws, soil and water conservation, construction of drainage, controlled burning, community-based organizations, logging ban, coordination among local government units, information sharing, development of water sources, research and capacity building, provision of relief goods, creation of task forces, and infrastructure repair and construction.

More interestingly, local governments saw themselves playing a key role in ensuring the success of adaptation measures in different sectors such as water and forest. The most important lessons from the survey concern the need to examine the tradeoffs across adaptation options, involve community members to lower costs of interventions, and effectively represent local needs to policy makers and external actors. (Source: Lasco et al. 2006)

A review of the United Nations Framework Convention on Climate Change (UNFCCC) database on coping and adaptation practices of local actors suggests that external interventions fall into four different groups. ${ }^{6}$ Perhaps the most obvious of these is information about climate variability and change to help reduce unpredictability associated with climate-events and trends. Governments can provide such information effectively, as also information about different adaptation options and resources that might be available to help local actors adapt. A second set of external interventions are technical advances that may lead to higher crop or resource productivity, reduce costs of undertaking some adaptations, or improve the efficiency of existing adaptation practices. Financial and investment supports can make the adoption of technological changes more widespread, provide incentives to diversify, enable new infrastructure that can facilitate storage or diversification, or subsidize existing adaptation practices, and so forth. Finally, leadership and institutional interventions can help reduce the costs of collective action for communal pooling, or for any of the other classes of adaptation practices. Clearly, new funding flows are only one, if at times critical means to facilitate adaptation or enhance adaptive capacity. 


\section{Types of Rural Institutions}

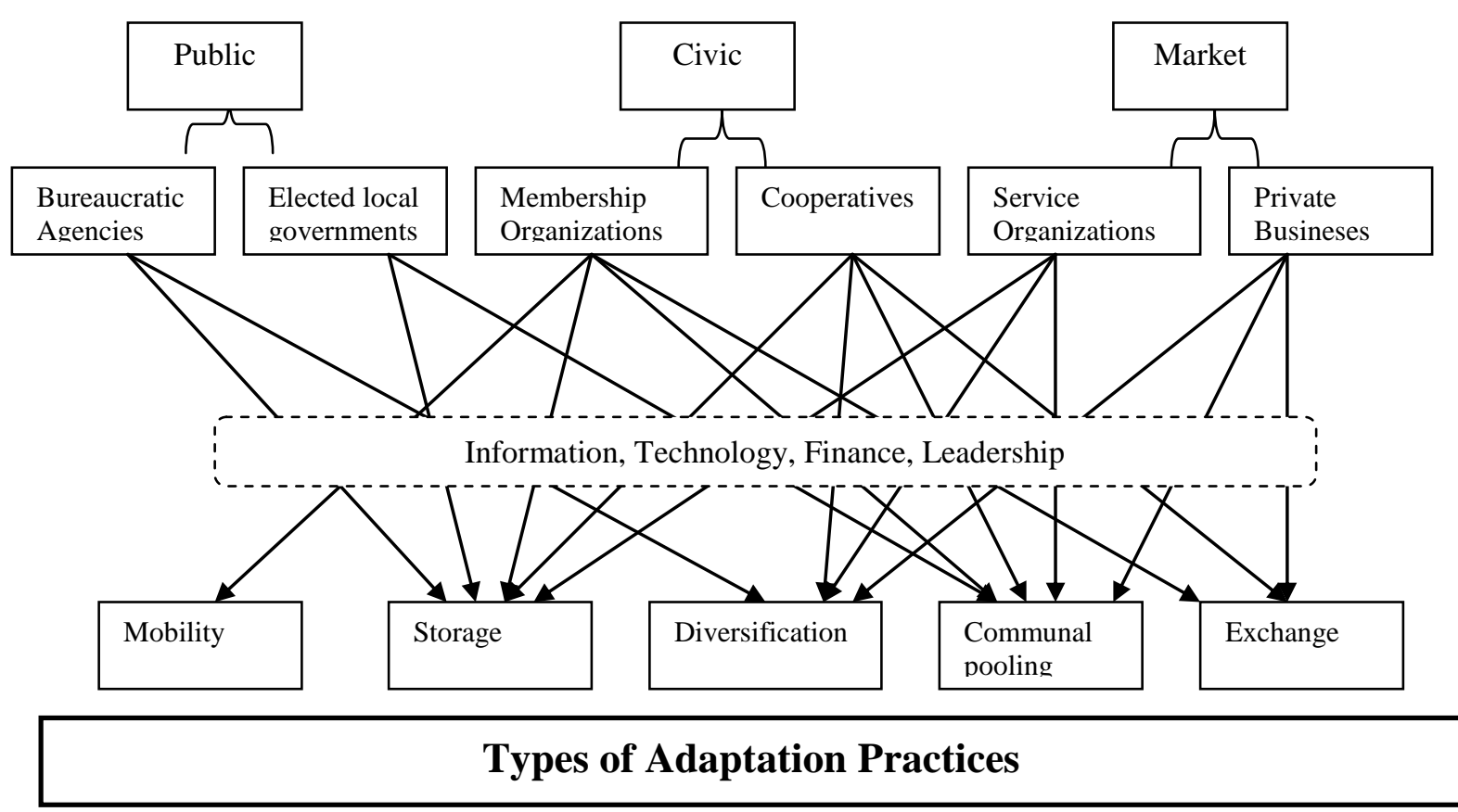

Figure 5: Institutional Mediation of External Interventions to Facilitate Adaptation

The figure above takes the right half of figure 1 as the domain relevant for external interventions and presents the four main external interventions to reinforce adaptation practices: information and training, technological innovation, financial investment, and leadership and institutional changes that reduce costs of collective action. These interventions can be viewed as mechanisms to provide resources necessary to enhance adaptive capacity. Whether they actually increase adaptive capacity of resilience will depend on the manner in which they become available, the people who gain access to them, and the institutional means of their provision.

Again, using the data from the UNFCCC database on coping strategies (see table 9 below), the figure suggests that public sector institutions are more likely to facilitate adaptation strategies related to communal pooling, diversification, and storage owing to their command over authoritative action, and ability to channel technical and financial inputs into rural areas. Civic sector institutions may be more flexible that those in either private or public sector because of the ability to redefine goals and adopt new procedures. Depending on need they can help strengthen all the different adaptation strategies. Finally, private sector organizations, because of their access to financial resources, are more likely to have greater expertise in promoting exchange and diversification, but may also be able to advance communal pooling if one takes into account not-for-profit service organizations.

\section{Adaptation, Institutions, and Livelihoods Framework: Case Evidence}

This section uses evidence from two sets of cases - those in the UNFCCC coping strategies database, and in the National Adaptation Programmes of Action (NAPAs) to comparatively assess the role of local rural institutions in facilitating adaptation. Both data are based on the work of the UNFCCC which is perhaps the most important framework international treaty on climate change. Most countries joined the UNFCCC more than a decade ago to begin to consider what can be done to reduce global warming and cope with inevitable climate changes. The Kyoto Protocol was an addition to the UNFCCC and commits its 
signatories to more powerful and legally binding measures. The UNFCCC secretariat supports institutions involved in the climate change process, particularly the Conference of Parties and other subsidiary bodies (http://unfccc.int/essential_background/items/2877.php).

The UNFCCC database on coping strategies provides a useful review and summary of 118 cases of adaptation worldwide. ${ }^{7}$ These cases form a useful empirical basis for examining the distribution of adaptation practices, the role of local institutions in facilitating adaptation, and how institutions mediate between external interventions and improvements in local adaptive capacity. These cases are distributed across 46 countries, with the preponderance of the cases from Africa (45) and Asia (58). The specific adaptation strategies identified and discussed in the 118 cases can be classified either as individual illustrations or examples of combinations of the five different categories of adaptation practices described earlier: mobility, storage, diversification, communal pooling, and exchange (Annex Figure 1 at the end of the report shows the distribution of the adaptation cases around the world).

\subsection{Analysis and observations of the UNFCCC data}

The evidence in the cases presents some useful, even provocative patterns. Perhaps the most interesting ones concern the near complete absence of mobility in the examined cases (see table 4), and the occurrence of exchange only in combination with at least one other type of adaptation practice. It makes intuitive sense that as an adaptation practice, exchange should be possible only when households and communities have also adopted other adaptation practices to make something available for exchange. Table 4 also suggests that the most common classes of adaptation responses are diversification and communal pooling on their own, and diversification and exchange as a pair.

\begin{tabular}{|c|c|c|}
\hline \multicolumn{3}{|c|}{$\begin{array}{l}\text { Table 4: Frequency Distribution of Different Classes of Adaptation Practices } \\
(\mathrm{N}=118)\end{array}$} \\
\hline $\begin{array}{l}\text { Class of Adaptation } \\
\text { Practice }\end{array}$ & Corresponding Adaptation strategies & Frequency* \\
\hline Mobility & $\begin{array}{l}\text { 1. agropastoral migration } \\
\text { 2. wage labor migration } \\
\text { 3. involuntary migration }\end{array}$ & 2 \\
\hline Storage & $\begin{array}{l}\text { 1. water storage } \\
\text { 2. food storage (crops, seeds, forest products) } \\
\text { 3. animal/live storage } \\
\text { 4. pest control }\end{array}$ & 11 \\
\hline Diversification & $\begin{array}{l}\text { 1. asset portfolio diversification } \\
\text { 2. skills and occupational training } \\
\text { 3. occupational diversification } \\
\text { 4. crop choices } \\
\text { 5. production technologies } \\
\text { 6. consumption choices } \\
\text { 7. animal breeding }\end{array}$ & 33 \\
\hline Communal pooling & $\begin{array}{l}\text { 1. forestry } \\
\text { 2. infrastructure development } \\
\text { 3. information gathering } \\
\text { 4. disaster preparation }\end{array}$ & 29 \\
\hline Exchange & $\begin{array}{l}\text { 1. improved market access } \\
\text { 2. insurance provision } \\
\text { 3. new product sales } \\
\text { 4. seeds, animal, and other input purchases }\end{array}$ & 1 \\
\hline Storage and diversification & \multirow{5}{*}{$\begin{array}{l}\text { Examples of combinations of adaptation classes are drawn } \\
\text { from the strategies listed above. }\end{array}$} & 6 \\
\hline $\begin{array}{l}\text { Storage and communal } \\
\text { pooling }\end{array}$ & & 4 \\
\hline Storage and exchange & & 5 \\
\hline $\begin{array}{l}\text { Diversification and } \\
\text { communal pooling }\end{array}$ & & 4 \\
\hline Diversification and & & 25 \\
\hline
\end{tabular}




\begin{tabular}{|l|l|l|}
\hline exchange & \multirow{5}{*}{} & \\
\cline { 1 - 1 } \cline { 3 - 3 } Unidentified & & 2 \\
\hline Total & & \\
\hline
\end{tabular}

The data also show other interesting patterns.

In nearly all cases, local institutions are required to enable households and social groups to deploy specific adaptation practices (see table 5). In 77 cases, the primary structuring influence for adaptation flows from local institutions. In 41 cases, local institutions work in conjunction with external interventions.

In all cases where external support is present, it is channeled through local formal and informal institutions to enable adaptation. The inference is evident - without local institutions, rural poor groups will find it far costlier to pursue any adaptation practice relevant to their needs.

Table 5 also reveals a somewhat unexpected pattern in the UNFCCC data -- when rural institutions work in conjunction with external interventions, it is more likely that the distributional orientation of adaptation practice benefits will be the collective rather than the individual household.

\begin{tabular}{|l|l|l|l|}
\hline $\begin{array}{l}\text { Table 5: Distribution of Benefits from Adaptation Practices for Different Types of Local Institutions } \\
\text { (N=118) }\end{array}$ & $\begin{array}{l}\text { Individually oriented } \\
\text { benefits from adaptation } \\
\text { practices }\end{array}$ & $\begin{array}{l}\text { Collectively oriented } \\
\text { benefits from adaptation } \\
\text { practices }\end{array}$ & Total \\
\hline $\begin{array}{l}\text { Local institution } \\
\text { functioning in } \\
\text { conjunction with an } \\
\text { external intervention }\end{array}$ & 15 & 26 & 41 \\
\hline $\begin{array}{l}\text { Local institutions } \\
\text { without external } \\
\text { interventions }\end{array}$ & 55 & 22 & 77 \\
\hline Total & 70 & 48 & 118 \\
\hline Source: UNFCCC Coping strategies database & \\
\hline
\end{tabular}

Table 6 below indicates the distribution of the different adaptation practices according to the two ecological regions of interest: drylands and coastal areas. The information in the table suggests that at least in the context of the UNFCCC data, storage, and diversification are more often distributed in semi-arid areas as compared to adaptation strategies based on communal pooling. One reason for this may be the greater possibility of sudden and disastrous climatic hazards in coastal regions (storm surges, storms and cyclones, and coastal flooding compared to failure of rains or erratic rainfall which for all their suddenness unfold more slowly than a storm or a flood).

\begin{tabular}{|l|l|l|l|}
\hline \multicolumn{4}{|l|}{ Table 6: Distribution of Adaptation Strategies by Ecological Context (N=97)* } \\
\hline & Semi-Arid areas & Coastal areas & Total \\
\hline Storage & 8 & 1 & 9 \\
\hline Diversification & 18 & 7 & 25 \\
\hline Communal pooling & 8 & 17 & 25 \\
\hline $\begin{array}{l}\text { Storage and } \\
\text { diversification }\end{array}$ & 3 & 1 & 4 \\
\hline Storage and exchange & 5 & 0 & 5 \\
\hline $\begin{array}{l}\text { Diversification and } \\
\text { exchange }\end{array}$ & 15 & 7 & 22 \\
\hline Other & 4 & 3 & 7 \\
\hline Total & 61 & 36 & 97 \\
\hline $\begin{array}{l}\text { The remainder of the } 118 \text { cases in the Coping strategies database were from highland, irrigated, or cold } \\
\text { regions. } \\
\text { Source: UNFCCC Coping strategies database }\end{array}$ \\
\hline
\end{tabular}


Given the importance of institutions to adaptation practices, it is critical to attend to three issues. The first concerns the distribution of institutional types (public, private, civic) in facilitating local adaptation. The second relates to how different types of institutions relate to different classes of adaptation practices. The third issue concerns the importance of understanding the distribution of different types of institutions in relation to their mediating role for external interventions. Table 7, 8, and 9 provide an initial assessment in regards to these three questions on the basis of the UNFCCC data.

Table 7 provides a summary of the institutional involvement in adaptation practices at the local level. Two points stand out about the information in this table. The first is that a combination of civic and public+civic institutions are the ones most commonly involved in facilitating adaptation to climate change. Private or market institutions have played a relatively small role in facilitating or reinforcing adaptation. This pattern both highlights and echoes a common complaint in writing on climate change - that it is one of the most prominent examples of market failure. The data on coping strategies fron the UNFCCC also indicates that private and market actors have been relatively uninvolved in initiatives that would enhance the ability of local actors to adapt to climate change. This finding is simultaneously a challenge and opportunity to identify ways of creating incentives and partnerships involve the private sector and market actors more intimately in facilitating adaptation.

Figure 6: Formal vs Informal Institutions in Adaptation

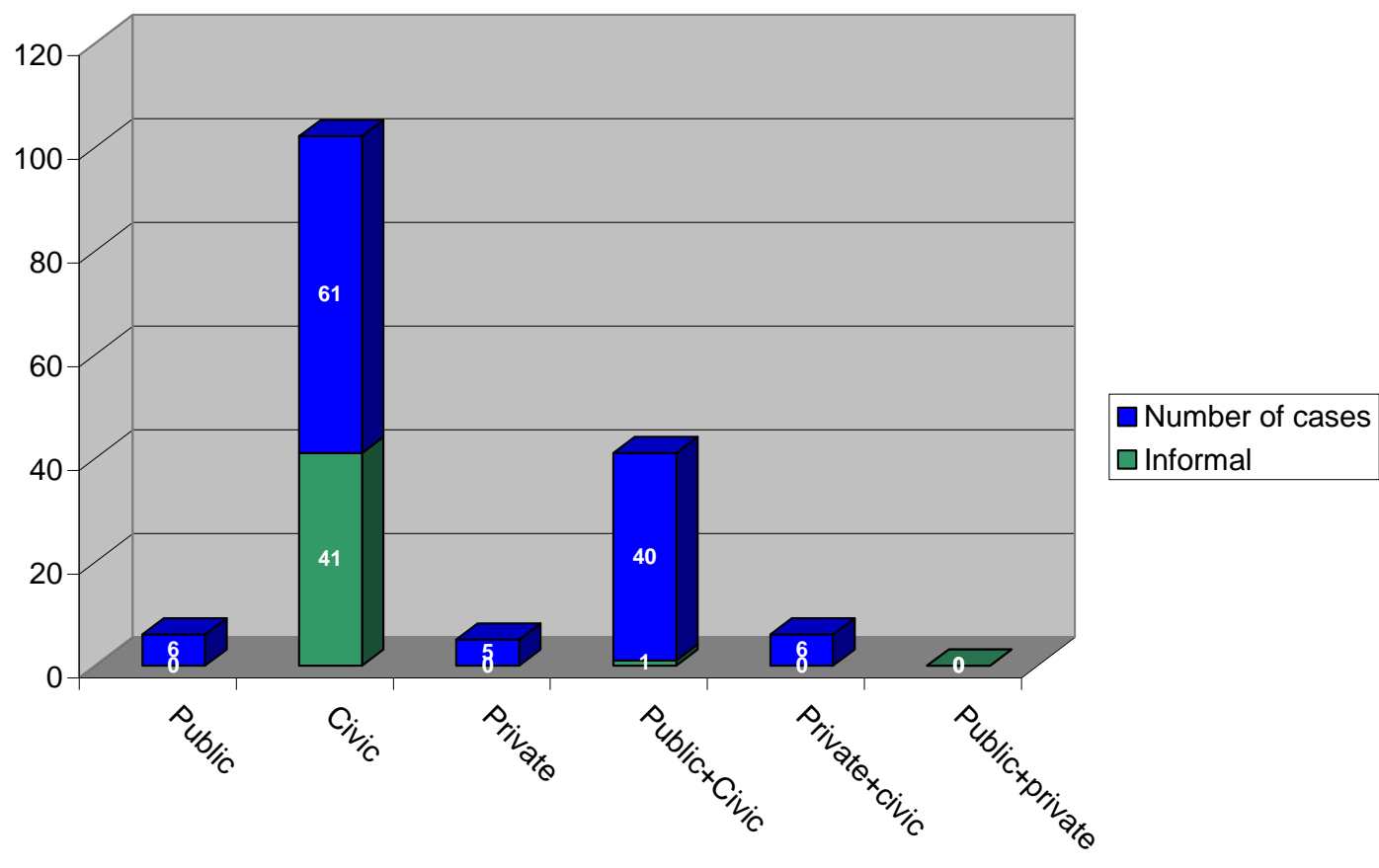

Another salient pattern in the data is that local level civic institutions, when functioning on their own often tend to be informal institutions. However, when public institutions are involved in adaptation practices, their relationship is far more often with formal civic institutions (see the distribution of formal and informal institutional arrangements for adaptation as reflected in the bars for civic and public+civic in figure 6 above). One of the implications of this data is that there are potentially significant gains to be made by identifying ways of encouraging informal processes through formal interventions to facilitate adaptation and greater adaptive capacity. Box 6 for example, provides one instance of such interactions where the formation of an informal collective group and initiation of small acts of joint action led to a more thoroughgoing effort at adaptation. In light of the data suggesting a lack of cases where formal interventions take advantage of informal processes at the local level, the lesson of the case in box 6 becomes even more interesting.

The second issue concerns how different types of institutions correlate with particular combinations of adaptation practices. The UNFCCC data does not provide detailed evidence on the subject. 
It is nonetheless possible to generalize in a preliminary way based on its information about how public, civic, and private rural institutions connect with different classes of adaptation practices (see table 7).

\begin{tabular}{|l|l|l|l|l|l|l|}
\hline \multicolumn{6}{|l|}{ Table 8: Combinations of Adaptation Practices and Institutions in the UNFCC database } \\
\hline & Public & Civic & Private & $\begin{array}{l}\text { Public and } \\
\text { civic }\end{array}$ & $\begin{array}{l}\text { Private and } \\
\text { civic }\end{array}$ & Total \\
\hline Storage & 0 & 8 & 0 & 3 & 0 & 11 \\
\hline Diversification & 0 & $\mathbf{1 9}$ & 1 & $\mathbf{1 2}$ & 1 & 33 \\
\hline $\begin{array}{l}\text { Communal } \\
\text { pooling }\end{array}$ & 4 & $\mathbf{1 1}$ & 0 & $\mathbf{1 4}$ & 0 & 29 \\
\hline $\begin{array}{l}\text { Storage and } \\
\text { diversification }\end{array}$ & 0 & 2 & 0 & 2 & 0 & 4 \\
\hline $\begin{array}{l}\text { Storage and } \\
\text { exchange }\end{array}$ & 0 & 4 & 0 & 1 & 1 & 6 \\
\hline $\begin{array}{l}\text { Diversification } \\
\text { and exchange }\end{array}$ & 0 & $\mathbf{1 3}$ & $\mathbf{4}$ & 5 & $\mathbf{4}$ & 26 \\
\hline Other & 2 & 4 & 0 & 3 & 0 & 9 \\
\hline Total & 6 & 61 & 5 & 40 & 6 & 118 \\
\hline Source: UNFCCC coping strategies database. &
\end{tabular}

Table 7 provides an empirical substantiation of the information presented visually in figure 4 . Although the UNFCCC database does not provide enough information to make a detailed assessment of the subdivisions within the broad categories of public, private, and civic institutions, it does suggest that public and market institutions do not promote mobility; ${ }^{8}$ that public institutions are only infrequently associated with market exchange processes promoting adaptation; and that when market actors are involved in adaptation practices, it is likely that they would assist exchange based efforts.

Given the overall distribution of institutional arrangements through which adaptation is facilitated at the local level, it is not surprising that much of the institutional action is focused around civic and a combination of public and civic institutions. A few points are still worth highlighting from the information in this table (the relevant cells have the numbers in bold in table 7). The first is that civic institutions and partnerships between civic and public institutions seem to occur more frequently to promote diversification and communal pooling. There are relatively few instances of civic institutions promoting storage or mobility, or for that matter a combination of different adaptive strategies. In contrast, much of the involvement of private institutions and the partnership between civic and private institutions seems to focus on the promotion of diversification and exchange. This is an expected finding in many ways - one expects market actors and processes to be most suited for exchange-based activities, and indeed this is also the finding in the data.

Table 8 provides a summary overview of how public, civic and private institutions mediate external interventions to promote adaptation. It focuses on the 41 out of the 118 cases in the dataset that clearly show the involvement of external actors in promoting adaptation (see table 5). The total number of cases is too small, therefore, to make broad generalizations, but in looking at the distribution of the specific cases based on the main patterns in the data, there are some useful lessons to be derived.

\begin{tabular}{|l|l|l|l|l|l|}
\hline $\begin{array}{l}\text { Table 8: Local Institutions and their Mediation of External Interventions to Promote Adaptation } \\
\text { (N=41) }\end{array}$ & Public & Civic & $\begin{array}{l}\text { Public and } \\
\text { civic }\end{array}$ & $\begin{array}{l}\text { Civic and } \\
\text { private }\end{array}$ & Total \\
\hline & 0 & 2 & 8 & 0 & 10 \\
\hline Information & 2 & 4 & 1 & 0 & 7 \\
\hline Technical inputs & 2 & 0 & 6 & 1 & 9 \\
\hline Financial support & 0 & 4 & 2 & 0 & 6 \\
\hline Information/Technical inputs & 0 & 4 & 1 & & 5 \\
\hline Technical Inputs and financial support & 0 & 2 & 2 & 0 & 4 \\
\hline Other & 0 & 16 & 20 & 1 & 41 \\
\hline Total & 4 & & & \\
\hline Source: UNFCCC Coping strategies database & \multicolumn{5}{|l|}{} \\
\hline
\end{tabular}


The information in the table above suggests that the major external interventions to support local adaptation efforts have focused on providing information and financial support. There are fewer cases in which a variety of external interventions have been combined to facilitate adaptation, and in no case have external actors provided strong leadership or attempted local institutional reconfiguration to support adaptation. A closer look at the data explains these patterns. The vast majority of cases of information provision and financial support concern adaptation practices related to disaster preparedness, early warning systems about failure of rains, and private or public infrastructure that could withstand climate hazards such as floods and storms. Certainly, the role of external interventions in promoting adaptation is not exhausted by these three types of adaptation to the threat of climate change. As indicated by the list of specific adaptation strategies in table 4, itself only a subset of the different types of adaptation practices that rural populations have already been attempting, there are many more ways in which external support can reinforce adaptation efforts and support institutions that are shaping, facilitating, and reinforcing local adaptation efforts. The conclusion is inescapable that external forms of support focus on an incredibly small slice of the huge diversity of adaptation mechanisms that local actors and institutions are inventing and attempting.

The tables and figures above allow several inferences based on the information contained in possibly the largest existing database on local adaptation strategies. These inferences concern the distribution of five adaptation strategies as discussed earlier in this paper, the distribution of these strategies in different regions, the relationship between adaptation strategies and local institutions, and the relationship between different types of local institutions and how they mediate external interventions to facilitate adaptation. Three of the more important implications of these data are worth reiterating. 1) local institutions are critical to the successful pursuit of local and implementation of externally facilitated adaptation strategies. Without the support of local institutions, it is highly unlikely that adaptation can even be pursued, let alone pursued successfully. 2) Civil, and informal institutions are key mechanisms to achieve most forms of adaptation, and to enhance adaptive capacity. They play an extremely important role in adaptation both in semi-arid and in coastal regions, albeit for different kinds of adaptation options. But they seem necessary components of any externally introduced intervention to enhance adaptive capacity, often in collaboration with other types of institutions. 3) Available data do not possess sufficient detail to make fine distinctions about the characteristics of institutions that are most important in pursuing adaptation, but they still suggest the highly underexploited strengths of the private sector and market forces in helping enhance adaptive capacity in marginal environments.

The analysis of the data also provides some key insights in relation to external interventions for adaptation. It suggests that interventions need to be channeled through appropriate local institutions, and that partnerships between civil society and public institutions have been extremely important in helping local populations adapt to environmental variability. The data also suggests a potentially significant role for partnerships involving private and civil society institutions, especially in relation to adaptation strategies relying on exchange mechanisms.

\section{$\underline{6.2 \text { Discussion of the NAPA cases }}$}

The adaptation projects collected in the National Adaptation Programs of Action (NAPA) documents have been developed by ministries of environment in different countries. They represent the most extensive and serious policy effort to date to identify priority areas for adaptation interventions. These cases present an opportunity to examine how existing efforts to plan for climate change address the role of institutions in adaptation. The NAPA documents provide information from 16 countries about the high priority adaptation projects chosen by the relevant government agencies in these countries. Collectively, these country governments identified close to 170 small and large projects with diverse objectives and implementation mechanisms. A common process of identification and prioritization was used in each country to identify and select the most important adaptation projects for the country governments. The figure below presents basic information about these projects concerning their thematic focus and numbers. 
Figure 7: Sector-wise NAPA Adaptation Projects

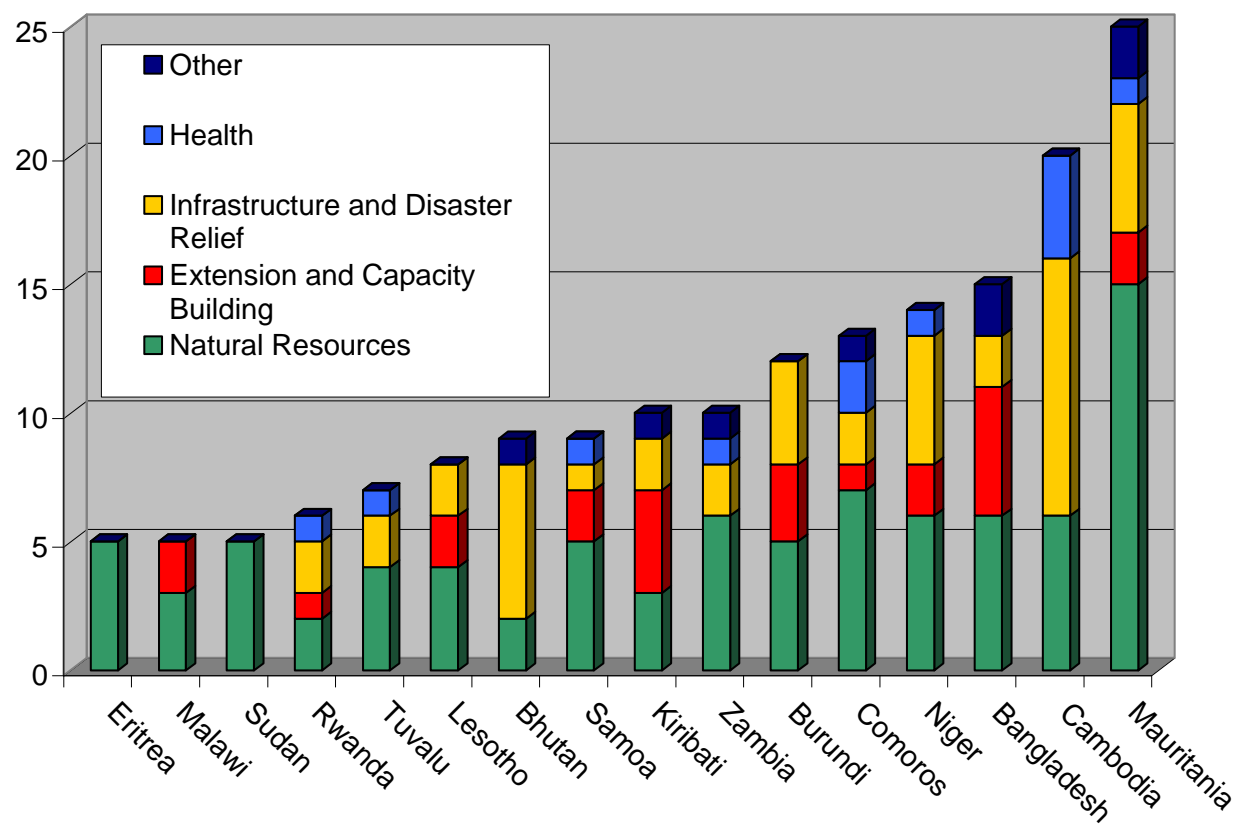

The figure shows that the largest number and proportion of adaptation projects are focused on sectoral issues related to improvements in natural resources related activities such as in agriculture, forestry, water conservation and irrigation, and in the development of infrastructure and disaster relief. Very few of the countries have identified urban impacts of climate change or new research on the best means of adaptation as high priority areas needing support.

Although a detailed analysis of these projects along the lines of the UNFCCC database is not possible given the nature of information presented in the NAPA documents, it is still possible to make basic comparisons that point to the ways the policy process has worked in different countries to engage with local institutions in the urgent issues surrounding adaptation in the context of climate change. First, in contrast to the actual instances of adaptation described and enumerated in the UNFCCC database, most of the projects in the NAPA documents seem far more aimed at building the capacity of national governments and agencies to coordinate adaptation, to provide services to the general population, or to create infrastructure rather than to strengthen the capacity of local actors and institutions to undertake adaptation. Figure 8 provides information on two areas of concern to this report - the extent to which selected high priority projects focus on communities, and the role they identify in the project design for community or local level public, private, or civic institutions.

Thus, local institutions are incorporated as the focus of adaptation projects in just about 20 percent of the projects described in the NAPA documents. The limited focus on local actors is especially striking when it comes to the anticipated role of local level institutions in adaptation. Only 20 of the 173 projects described in the NAPA reports identify local level institutions as partners or agents in facilitating adaptation projects. Indeed, given this minimal level of attention to local institutions - even for projects that 


\section{Figure 8: Relative Importance of Local Institutions in NAPA Adaptation Projects}

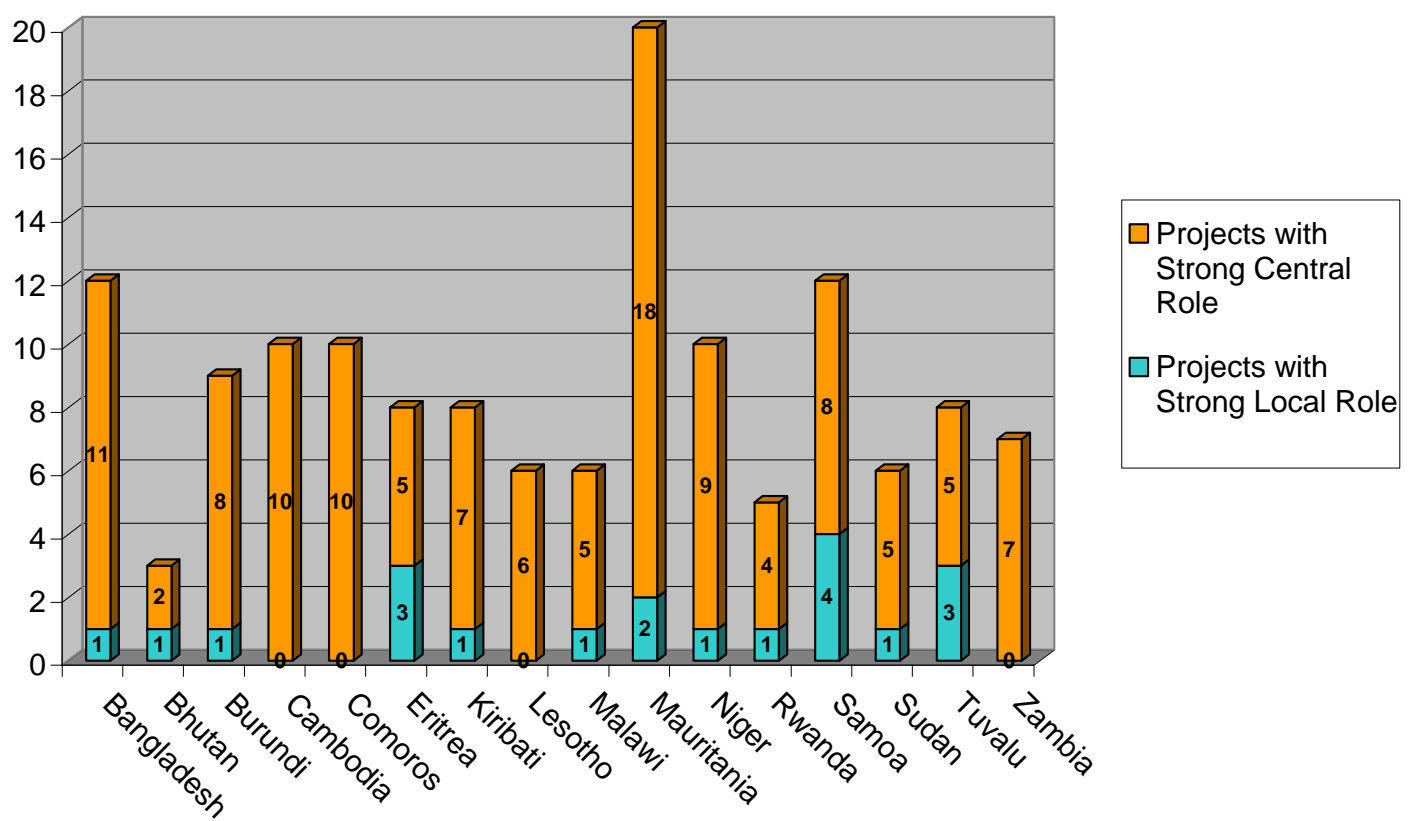

are focused on agriculture, water, forest management, fisheries, small scale infrastructure, and capacity building for which local institutions could be viewed as basic components of an adaptation strategy - it is perhaps unnecessary to develop a refined argument about local institutions and adaptation. Despite widespread consultations that went into the production of the NAPA documents, it appears that the process was attentive in only a limited manner to the historical experiences of adaptation, indigenous or local adaptation strategies, and forms of local and cross-scale vulnerabilities of marginal peoples. In any further efforts to develop national adaptation plans the potential role of local civic institutions and institutional partnerships both at the local level and across multiple scales must receive much greater attention than it has hitherto received.

The analysis of the information on high-priority projects selected by relevant ministries in the least developed countries as identified by the UNFCCC brings home the enormous ground that still has to be covered by the national planning process in relation to adaptation and local institutions. Despite an explicit commitment to grassroots processes and institutions that has been articulated in the NAPA process, the actual documents and projects have paid relatively limited attention to rural institutions. Not only do most projects not incorporate local communities and institutions in adaptation plans, little evidence of consultation and coordination between the local and national level can be seen in the descriptions of the selected high-priority projects. Given that only a small proportion of all NAPA documents have been finalized at present, there is both an opportunity to redress this gap in the process by identifying how rural institutions can play a more defining role in projects targeted toward rural areas, and to provide guidelines for other attempts to develop territorially based adaptation plans in which interactions among institutions would be important to analyze and understand. Because the World Bank is involved in some national level adaptation planning, it is especially useful to point to possible ways in which the analysis of NAPAs above may be useful - by calling for greater institutional coordination across levels, involvement of local institutional actors in project design and selection, and integration of different projects so as to promote a more holistic vision of adaptation in the context of climate-related threats to rural livelihoods.

\section{Relevance of the Analysis and the Findings for World Bank Operations}

Before presenting the main implications of the review for World Bank projects and operations, it is important to note that the examination of different types of World Bank projects is based on a limited review of selected documents, primarily for some investment projects. More careful analysis of the work 
that the World Bank is doing is necessary to develop a thorough understanding of the relevance of this report's findings even in the context of the Bank's investment projects.

Over the last two years, the issue of climate change and adaptation has come to assume increasing importance for the World Bank and for its development projects. Certainly, a number of projects within the World Bank have focused more or less directly on climate issues even since the late 1990s. But the ratio of projects and resources focusing on adaptation has historically been smaller than those committed to mitigation. As the interest in and importance of new work on adaptation increases, several elements of this report can be of relevance to development and adaptation projects implemented by the World Bank. These include a) the proposed classification scheme for adaptation practices and the relationship of adaptation practices to external interventions that seek to enhance adaptive capacity; b) the report's findings related to the role of institutions in supporting adaptation practices, enhancing adaptive capacity, and channeling external interventions; and c) the analytical approach adopted in the report to understand institutional access, institutional articulation, and the role of social network analysis in providing a better understanding of appropriate institutional leverage points for external interventions.

Before examining these implications of the report it may be useful to describe some of the current projects being implemented by the World Bank according to the scheme identified in figure 5, and based on timing and scope of efforts to improve adaptive capacity. Recall that the figure classifies different adaptation projects into four different cells depending on whether they are i) reactive and targeted, ii) proactive and targeted, iii) reactive and comprehensive, and finally, iv) proactive and comprehensive. These different types of projects have their own goals, and rely on specific mechanisms suitable for achieving their goals. The above classification is thus not intended by any means to suggest that all adaptation and development projects should aim to be proactive and comprehensive, or even that proactive and integrated projects are necessarily better than reactive and targeted ones. The goal, rather, is to identify the operational implications of the analysis of adaptation practices and institutions presented in this report.

Reactive and Targeted: Most disaster relief and emergency support projects fall in the first cell (reactive and targeted), but relatively few of the World Bank's projects can be classified into this cell. The work performed by many charitable and relief agencies, often in the wake of disasters, belongs properly to this class of interventions. Although local institutions also play a critical role in facilitating such interventions and making them more successful, this report does not examine them in any detail.

Proactive and Targeted: Interventions that are proactive and targeted seek to reduce vulnerabilities associated specifically with particular climate hazards, or to enhance resilience by focusing on specific sectors. Insurance schemes for managing hazards affecting agricultural risks, disaster risk management projects focusing on resilience in the wake of climate related disasters, and sectoral projects seeking to improve natural resource management all may belong to this class (see Box 12 on the Sahel Integrated Lowland Ecosystem Management project).

\section{Box 11: The Sahel Integrated Lowland Ecosystem Management (SILEM) project}

The SILEM project aims at sustainable improvements in the productive capacity of rural resources in Burkina Faso. It seeks to do so by focusing on the capacity and incentives of local governments and rural communities. GEF funds are earmarked in the project to improve community incentives for environmental management and conservation, and encourage the government to establish decentralized watershed management institutions. The project seeks also to improve inter-village coordination for watershed management, promote global partnerships supporting carbon sequestration and integrated ecosystem management, and thereby create conditions for scaling up to higher levels. The project has a sectoral focus. However, through this focus on ecosystems, also aims to create the conditions for sustainable rural development.

The major implications of this report for proactive and targeted Bank projects concern a better understanding and description of existing adaptation practices of rural populations, institutional mapping of local institutions to analyze institutional access and articulation, and better targeting of external resources toward more disadvantaged social groups.

Reactive and Integrated: These projects attempt to improve adaptive capacity in the wake of major climate-related disasters but by working to support institutional development, coordinate across institutional scales, improve integration of community and government efforts to support adaptation, and 
improve local adaptive capacities (see box 12 on the Nicaragua Natural Disaster Vulnerability Reduction Project).

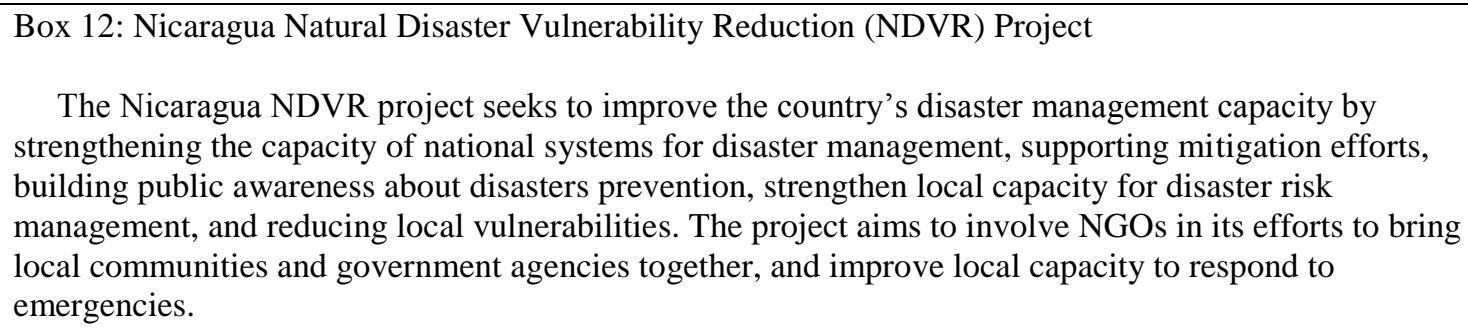

The Nicaragua NDVR project seeks to improve the country's disaster management capacity by strengthening the capacity of national systems for disaster management, supporting mitigation efforts, building public awareness about disasters prevention, strengthen local capacity for disaster risk management, and reducing local vulnerabilities. The project aims to involve NGOs in its efforts to bring local communities and government agencies together, and improve local capacity to respond to emergencies.

The most important implications of the analysis in this report for reactive and integrated projects concerns a better understanding and description of existing adaptation practices of local, especially rural populations, institutional mapping of local institutions to analyze institutional access and articulation, and thereby better targeting of external resources toward disadvantaged social groups, especially in terms of income, wealth, gender, age, and ethnicity, and use insights from such mapping to identify mechanisms to improve institutional coordination across scales. Finally, the NDVR project could also potentially improve its level of integration with other development interventions that seek to improve adaptive capacity more generally by improving the different kinds of resources available to local populations.

Proactive and Integrated: The final cell in figure 5 concerns projects that attempt to be proactive in terms of improving adaptive capacity, and comprehensive in their scope by attempting to improve livelihoods and production possibilities, undertaking institutional development, and adopting a territorially differentiated vision of development in which greater coordination of household responses through institutional strengthening would go together with modulation of policy initiatives to support adaptation. A good example of a project that focuses on livelihoods and adaptation to climate change in a proactive and comprehensive manner is the Kenya Adaptation to Climate Change in Arid Lands project (KACCAL), embedded within the Kenya Arid Lands and Resource Management Project (ALRMP) (see box 13).

\section{Box 13: The Kenya Adaptation to Climate Change in Arid Lands (KACCAL) project \\ The KACCAL project, in common with other adaptation projects recognizes that climate change may already be influencing climate-related hazards such as droughts in Kenya, and that the variability and uncertainty associated with climate is likely to increase. Because arid lands are especially vulnerable to climate risks, it seeks to focus on poorer households within these regions who are often locked into a vicious dynamic of disaster, poverty, and vulnerability. Its major goals are to to improve food security, reduce vulnerability to climate risks, and mainstream adaptation and risk management in government programs. At the same time, the project also aims to improve livelihoods opportunities and strengthen local institutions.}

Bank projects such as the KACCAL are also an example of the implications of the territorial development vision: transformation of productive possibilities and institutional development. The KACCAL project has also paid significant attention to the suite of adaptation practices used by households and has undertaken a examination of the role of local institutions in facilitating community and household level adaptation. Project documents also suggest that there has been an assessment of the role of local institutions in mediating external support. The major implications of this report for such projects concern the operational focus on the mapping of institutional access and articulation, and the identification of institutional leverage points to best channel external resources toward the most vulnerable groups.

The table below summarizes the relevant implications of this report's analysis for the three types of World Bank projects referenced above. The number of " $x$ 's" denotes a subjective assessment of the degree of relevance.

Table 9:

Operational Implications of Report's Analysis for Three Types of World Bank Projects 


\begin{tabular}{|l|l|l|l|}
\hline Project type & $\begin{array}{l}\text { Reactive and } \\
\text { integrated }\end{array}$ & $\begin{array}{l}\text { Proactive and } \\
\text { targeted }\end{array}$ & $\begin{array}{l}\text { Proactive and } \\
\text { integrated }\end{array}$ \\
\hline $\begin{array}{l}\text { Community level vulnerability assessment and } \\
\text { classification of adaptation practices }\end{array}$ & $\mathrm{x}$ & $\mathrm{x}$ & \\
\hline $\begin{array}{l}\text { Assessing role of institutions in enhancing } \\
\text { adaptive capacity }\end{array}$ & $\mathrm{xx}$ & $\mathrm{x}$ & $\mathrm{x}$ \\
\hline $\begin{array}{l}\text { Role of institutions in channeling external } \\
\text { interventions }\end{array}$ & $\mathrm{xx}$ & $\mathrm{x}$ & $\mathrm{x}$ \\
\hline $\begin{array}{l}\text { Use of institutional mapping to coordinate cross } \\
\text { scale institutional coordination }\end{array}$ & $\mathrm{xxx}$ & $\mathrm{xx}$ & $\mathrm{xx}$ \\
\hline $\begin{array}{l}\text { Use of institutional mapping to understand } \\
\text { institutional access and articulation }\end{array}$ & $\mathrm{xxx}$ & $\mathrm{xx}$ & $\mathrm{Xx}$ \\
\hline $\begin{array}{l}\text { Use of institutional mapping to identify } \\
\text { appropriate institutional leverage points }\end{array}$ & $\mathrm{xxx}$ & & \\
\hline
\end{tabular}

\section{Conclusion}

Impacts of ongoing climate change will greatly increase the vulnerability of poorer, more marginal households in developing world. The planetary scale of climate change notwithstanding, its impacts will be spatially highly differentiated - increasing average temperatures will hide a diversity of variations in impacts on regions, communities, and households. This is because vulnerability to climate change is socially and institutionally determined, even when provoked biophysically. This is why adaptation to the inevitable impacts of climate change is unavoidably local, and it is also why local rural institutions have a critically important role in promoting effective adaptation and enhancing adaptive capacity of vulnerable rural populations.

Despite the critical importance of rural institutions in shaping the adaptive response of humanity to climate change and variability, the literature on the subject is in its infancy. This paper has reviewed the state of knowledge on the role and importance of institutions in adaptation to generate three key findings.

If adaptation is unavoidably local, it also always occurs in an institutional context. Rural institutions are crucial in shaping adaptation and its outcomes. They are crucial as mediating bodies that connect households to local resources, determine how flows of external support will be distributed among different social groups, and link local populations to national policies and interventions. In this context, the existing role of public and civic local institutions needs emphasis, and new incentives are needed to promote the involvement of private organizations and institutions in facilitating adaptation.

The paper also finds that existing national plans to promote adaptation to climate change have been mostly inattentive to the role of local institutions in adaptation, or about their links to local populations and national policies. As a result, despite a stated commitment to grassroots involvement, the actual focus in national adaptation plans is on technical and infrastructure options for adaptation, with little attention to their social and institutional context. Future national-level efforts to develop adaptation plans need to consider the role of local institutions more centrally if they seek to serve the needs and interests of the most vulnerable populations better.

A third finding of the review is related to its focus on institutional access and articulation - that is, the ways in which different social groups are connected to rural institutions and how the institutions in a given location are interconnected. For adaptation projects achieve their goals effectively - whether the goal is improved adaptive capacity or reduced vulnerability of the poorer households - a better understanding of institutional access and articulation is essential. Such an understanding is helpful in uncovering the most effective institutional leverage points, and shaping the mechanisms through which external resources can facilitate adaptation and greater resilience.

These findings of the report lead to a number of implications for incorporating local institutions more closely in the context of adaptive development. These have been described briefly already in the executive summary, but are worth reiterating.

For more effective adaptation it is necessary to:

Support a greater role for institutional partnerships. Such partnerships are crucial to local adaptation. More specifically, partnerships among local public and civil society institutions are associated more closely with adaptation practices related to diversification and communal pooling. Partnerships 
between private and civil society institutions are relatively uncommon and need encouragement. They tend to be more closely associated with exchange and storage based adaptation practices.

Enhance local institutional capacities. Because the nature and intensity of future climate impacts are likely to be more adverse than what existing climate variability indexes, external support is necessary to promote institutional adaptive capacities.

Understand local institutional articulation and access patterns before providing resource support in any development project. Vulnerable groups in general have lower institutional access than do those who are more powerful or better off. Before external support for greater adaptive capacity is made available, therefore, an analysis of the nature of institutional linkages and access for different social groups becomes critical. Such analysis can help target adaptation investments better.

Improve institutional coordination across scales. National plans for adaptation need to involve local institutions more centrally in planning for and implementing adaptation policies and projects. At the very least, there must be far greater coordination between adaptation policies and measures adopted by institutions and decision makers at the national level, and their counterparts at the local level.

Focus on territorial development strategies taking both vulnerabilities and capacities into account. Interventions for improving adaptive capacity in the context of development projects need to attend better to adaptation practices facilitated by different forms of external support. The multiple linkages among external interventions and local adaptations can only be understood through a focus on the mediating role of different institutions in a given territory, and their influence on production and adaptation possibilities.

Adopt an adaptive perspective on institutional development. Given the relatively newness of research on adaptation and institutions, improvements in existing knowledge and the development of greater adaptive capacity will require a willingness to experiment, tolerate mistakes, and promote social learning.

This report also identifies three areas in which far more research is needed to improve existing knowledge about the role of institutions in adaptation and adaptive development.

The first of these concerns the sheer lack of in-depth empirical and comparative work on adaptation and institutions. Although it is clear that adaptation to climate change will require tremendous social and institutional adjustments in the coming decades, the state of knowledge on the subject is in no more than its infancy. This paper has made no more than a beginning in thinking about the important conceptual bases for thinking about adaptation in relation to the livelihoods of the rural poor, ways to think about rural institutions in the context of adaptation, and the specific effects of rural institutions on adaptation practices. We still know relatively little about each of these areas, let alone how institutional access and articulation shape adaptive capacity and external interventions. The tentative findings of this paper need more work on these issues.

The second area of research concerns the idea of adaptive development which the review suggests as a means through which to improve the ability of households and social groups to address risks, but also improve livelihoods. The nature of institutions necessary to facilitate adaptive development, however, remains unclear. Are current institutional arrangements at different scales appropriate to improve risk management capacity of different actors? How can institutions incorporate risk management more urgently in their mandate? What are the institutional changes necessary to bring the urgency of adaptation to climate risks home to those who are likely to be affected by such risks most? Answers to these questions require more in depth research than is currently available.

Finally, there is broad agreement in the literature on climate change that it will produce both sudden and slow-onset impacts. Far more work remains to be done on how institutions across scales can coordinate human responses to these two broad types of climate impacts. In the case of climate hazards such as droughts, floods, storms, and hurricanes, the conventional response has been disaster relief, disaster risk management, and emergency support to affected regions and populations. Greater adaptive capacity is seen as the appropriate answer to climate hazards that unfold more slowly - increasing average temperatures, erratic rainfall, or rise in sea levels. The best ways to increase adaptive capacity to withstand both kinds of climate hazards and the role of institutions in such integration is little understood at present. A vision of territorial development that focuses both on the needs of households and communities in a given territory and their specific vulnerabilities and capacities is crucial in moving toward the answers about how disaster risk management and adaptive development can be integrated. 


\section{References}

Adger, W. N. 1999. Social vulnerability to climate change and extremes in coastal Vietnam, World Development 27(2): 249-69.

Adger, W.N., 2000a. Social and ecological resilience: Are they related? Progress in Human Geography 24 (3): $347-364$.

Adger, W. N. 2000b. Institutional adaptation to environmental risk under the Transition in Vietnam. Annals of the Association of American Geographers 90(4): 738-58.

Adger, W. N. 2003. Social capital, collective action, and adaptation to climate change. Economic Geography 79: 387-404.

Adger, W.N., 2006. Vulnerability. Global Environmental Change 16 (3): 268-281.

Adger, W. N., N. W. Arnell, and E. L. Tompkins. 2005. Successful adaptation to climate change across scales. Global Environmental Change 15: 77-86.

Adger, W.N., S. Agrawala, M.M.Q. Mirza, C. Conde, K. O'Brien, J. Pulhin, R. Pulwarty, B. Smit and K. Takahashi, 2007: Assessment of adaptation practices, options, constraints and capacity. Climate Change 2007: Impacts, Adaptation and Vulnerability. Contribution of Working Group II to the Fourth Assessment Report of the Intergovernmental Panel on Climate Change, M.L. Parry, O.F. Canziani, J.P. Palutikof, P.J. van der Linden and C.E. Hanson, Eds., Cambridge University Press, Cambridge, UK, 717-743.

Agrawal, A. 1999. Greener Pastures. Durham: Duke University Press.

Agrawal, A. 2001. 2001. Common Property Institutions and Sustainable Governance of Resources. World Development 29(10): 1649-72.

Agrawal, A., and M. Lemos. 2007. A Greener Revolution in Making? Environmental Governance in the $21^{\text {st }}$ Century." Environment 49(5): 36-45

Alland, A. 1975. Adaptation. Annual Review of Anthropology 4: 59-73.

Ashley, C. \& Carney, D. 1999. Sustainable livelihoods: Lessons from early experience. London: Department for International Development (DFID).

http://www.livelihoods.org/info/docs/nrcadc.pdf)

Bakker, K. (Ed.), 1999. A Framework for Institutional Analysis. Working Paper \#3, Societal and Institutional Responses to Climate Change and Climate Hazards:Managing Changing Flood and Drought Risk (SIRCH), Environmental Change Unit, University of Oxford.

Baland, J. M. and J. P. Platteau. 1996. Halting Degradation of Natural Resources: Is There a Role for Rural Communities? Oxford: Clarendon Press.

Batterbury, S. and T. Forsyth. 1999. Fighting back: Human adaptations in marginal environments, Environment 41(6): 7-30.

Bebbington, A. 1999. Capitals and capabilities: A framework for analyzing peasant viability, rural livelihoods and poverty, World Development 27(12): 2021-44.

Behnke, R. H., I. Scoones and C. Kerven. (eds) Range Ecology at Disequilibrium. London: Overseas Development Institute.

Berkes, F., and D. Jolly. 2001. Adapting to climate change: Social-Ecological resilience in a Canadian western Arctic community. Conservation Ecology 5(2): 18. [online] URL:

http://www.consecol.org/vol5/iss2/art18 
Berkes, F., Folke, C. (Eds.), 1998. Linking Social and Ecological Systems: Management Practices and Social Mechanisms for Building Resilience. Cambridge University Press, Cambridge, UK.

Berkes, F., Colding, J., Folke, C. (Eds.), 2003. Navigating Socialecological Systems: Building Resilience for Complexity and Change. Cambridge University Press, Cambridge, UK.

Blaikie, P., T. Cannon, I. Davis, and B. Wisner. 1994. At Risk: Natural Hazards, People's Vulnerability, and Disasters. Routledge, New York, NY.

Blanco, Ana. 2006. Local initiatives and adaptation to climate change. Disasters 30(1): 140-47.

Bohle, H. G., T. E. Downing, and M. J. Watts. 1993. Climate change and social vulnerability. Global Environmental Change 4(1): 37-48.

Brooks, N. 2003. Vulnerability, risk, and adaptation: A conceptual framework. Working Paper 38. Norwich: Tyndall Center for Climate Research.

Brooks, N., W. N. Adger, and P. M. Kelly. 2005. The determinants of vulnerability and adaptive capacity at the national level and the implications for adaptation. Global Environmental Change 15: 151-63.

Bryant, C., B. Smit, M. Brklacich, T. Johnston, J. Smithers, Q. Chiotti, B. Singh. 2000. Adaptation in Canadian agriculture to climate variability and change. Climatic Change 45: 181-201.

Butzer, K.W. 1980. Adaptation to global environmental change. Professional Geographer 32: 269-78.

Chiotti, Q., T. Johnston, B. Smit and B. Ebel, Agricultural response to climate change: A preliminary investigation of farm-level adaptation in southern Alberta. In: B. Ilbery, Q. Chiotti and T. Rickard, Editors, Agricultural restructuring and sustainability, CAB International, Oxon and New York (1997), pp. 201218.

Clark, W.C. 1985. Scales of climate impacts. Climatic Change 7 (1), 5-27.

Cutter, S.L., 1996. Vulnerability to environmental hazards. Progress in Human Geography 20 (4): 529-39.

Cutter, S.L., 2003. The vulnerability of science and the science of vulnerability. Annals of the Association of American Geographers 93 (1): 1-12.

Davies J. and R. Bennett. 2007. Livelihood adaptation to risk: Constraints and opportunities for pastoral development in Ethiopia's Afar region. Journal of Development Studies 43 (3): 490-511.

de Janvry, A. and E. Sadoulet. 2004. Toward a territorial approach to rural development: International experiences and implications for Mexico's micro-regions strategy. Mimeo. University of California, Berkeley.

Denevan, W.M. 1983. Adaptation, variation and cultural geography. Professional Geographer 35 (4): 399406.

Dixon, R. K., J. Smith, and S. Guill. 2003. Life on the edge: Vulnerability and adaptation of African ecosystems to global climate change. Mitigation and Adaptation Strategies for Global Change 8: 93-113.

Downing, T. E., M. J. Watts and H.G. Bohle. 1996. Climate change and food insecurity: Towards a sociology and geography of vulnerability. In: T.E. Downing, Editor, Climate change and world food security, Springer-Verlag, Berlin. Pp. 185-206.

Droogers, P. 2004. Adaptation to climate change to enhance food security and preserve environmental quality: Example for southern Sri Lanka. Agricultural Water Managment 66(1): 15-33. 
Eakin H. 2005. Institutional change, climate risk, and rural vulnerability: Cases from Central Mexico. World Development 33(11): 1923-38.

Eakin H, C. Tucker, and E. Castellanos. 2006. Responding to the coffee crisis: A pilot study of farmers' adaptations in Mexico, Guatemala, and Honduras. Geographical Journal 172: 156-71 Part 2.

Eakin, H. 2003. The social vulnerability of irrigated vegetable farming households in Central Puebla, Journal of Environment and Development 12:(4): 414-29.

Easterling, W. and M. Apps. 2005. Assessing the consequences of climate change for food and forest resources: A view from IPCC. Climate Change 70(1-2): 165-89.

Ellis, F. 2000. Rural Livelihoods and Diversity in Developing Countries. Oxford: Oxford University Press.

Food and Agriculture Organization (FAO). 2003. People-centred approaches: A brief literature review and comparison of types." LSP Working Paper 5.

Fraser, E. D. G. 2007. Traveling in antique lands: Using past famines to develop an adaptability/resilience framework to identify food systems vulnerable to climate change. Climatic Change 83(4): 495-514.

Glantz, M. H. 1990. On the interactions between climate and society. Population and Development Review 16 (supp.): 179-200.

Global Environment Facility (GEF). 2000. Operational Program \#13: Conservation and Sustainable Use of Biological Diversity Important to Agriculture. Nairobi: United Nations Environment Program.

Gunderson, L.H., Holling, C.S., Light, S.S. (Eds.), 1995. Barriers and Bridges to the Renewal of Ecosystems and Institutions. Columbia University Press, New York, NY.

Hardy, J. T. 2003. Climate Change: Causes, Effects, and Solutions. John Wiley.

Holling, C.S., 1973. Resilience and stability of ecological systems. Annual Review of Ecology and Systematics 4: 1-23.

Holling, C.S. and G. K. Meffe. 1996. Command and control and the pathology of natural resource management. Conservation Biology 10 (2): 328-337.

Holzmann, R. and S. L. Jorgensen. 2000. Social risk management: A new conceptual framework for social protection and beyond (Discussion Paper No. 0006). Washington, DC: Social Protection Unit, World Bank.

Howden, S. M., J. F. Soussana, F. N. Tubiello, et al. 2007. Adapting agriculture to climate change.

Proceedings of the National Academy of Sciences 104(50): 19691-96.

Hulme, M., R. Doherty, T. Ngara, M. New, and D. Lister. 2001. African climate change: 1900-2100. Climate Research 17:145-68

IFAD. 2003. Transforming Rural Institutions in Order to Reach the Millennium Development Goals. Discussion paper. International Fund for Agricultural Development, Rome..

Intergovernmental Panel on Climate Change (IPCC) 2007a: Climate Change 2007: The Physical Science Basis. Contribution of Working Group I to the Fourth Assessment Report of the Intergovernmental Panel on Climate Change Solomon, S., D. Qin, M. Manning, Z. Chen, M. Marquis, K.B. Averyt, M. Tignor and H.L. Miller (eds.). New York: Cambridge University Press. 
Intergovernmental Panel on Climate Change (IPCC) 2007b: Climate Change 2007: Impacts, Adaptation and Vulnerability. Contribution of Working Group II to the Fourth Assessment Report of the Intergovernmental Panel on Climate Change. M.L. Parry, O.F. Canziani, J.P. Palutikof, P.J. van der Linden and C.E. Hanson, Eds. Cambridge: Cambridge University Press.

International Development Research Council (IDRC). 1992. Our Common Bowl: Global Food Interdependence. Ottawa: IDRC.

Ivey, J. L., J. Smithers, R. C. de Loe, and R. D. Kreutzwiser. 2004. Community capacity for adaptation to climate-induced water shortages: Linking institutional complexity and local actors. Environmental Management 33(1): 36-47.

Janssen, M. A., M. L. Schoon, W. Ke, and K. Borner. 2006. Scholarly networks on resilience, vulnerability, and adaptation within the human dimensions of global change program. Global Environmental Change 16: $240-52$.

Kates, R. 2000. Cautionary tales: Adaptation and the global poor, Climatic Change 45 (2000) (1), pp. 517.

Kaylen, M. S., J.W. Wade, and D.B. Frank. 1992. Stochastic trend, weather and us corn yield variability. Applied Economics 24 (5): 513-18.

Kelly, P. M. and W. N. Adger. 2000. Theory and practice in assessing vulnerability to climate change and facilitating adaptation. Global Environmental Change 47(4): 325-52.

Lasco, R. D., R. V. O. Cruz, J. M. Pulhin, and F. B. Pulhin. 2006. Tradeoff analysis of adaptation strategies for natural resources, water resources, and local institutions in the Philippines. AIACC Working Paper No. 32. Washington DC: International START Secretariat.

Leichenko, R. and K. O'Brien. 2002. The dynamics of rural vulnerability to global change: The case of Southern Africa, Mitigation and Adaptation Strategies for Global Change 7 (2002), pp. 1-18.

Liverman, D. M. 2001. Vulnerability to global environmental change. In: J.X. Kasperson and R.E.

Kasperson, Editors, Global environmental risk, United Nations University, Tokoyo. Pp. 201-216.

McCarthy, J .J., Canziani, O.F., Leary, N.A., Dokken, D.J., White, K.S. (Eds.), 2001. Climate Change 2001: Impacts, Adaptation, Vulnerability. Cambridge University Press, Cambridge, UK.

McGregor, JoAnn. 1994. Climate change and involuntary migration: Implications for food security. Food Policy 19(2): 120-32.

Markowitz, H. M. 1952. Portfolio selection. Journal of Finance 7 (1): 77-91.

May, R. M., 1977. Thresholds and breakpoints in ecosystems with a multiplicity of stable states. Nature 269: 471-477.

Mendelsohn, R., A. Basist, P. Kurukulasuriya, and A. Dinar. 2007. Climate and rural income. Climatic Change 81(1): 101-18.

Meze-Hausken, E. 2000. Migration caused by climate change: How vulnerable are people in dryland areas? Mitigation and Adaptation Strategies for Climate Change 5(4): 379-406.

Mills, E. 2007. Synergisms between climate change mitigation and adaptation: An insurance perspective. Mitigation and Adaptation Strategies for Global Change 12: 809-42. 
Mortimore, M. 1989. Adapting to drought: Farmers, famines and desertification in West Africa, Cambridge University Press, Cambridge.

Mortimore, M. and W. M. Adams. 2001. Farmer adaptation, change, and crisis in the Sahel. Global Environmental Change 11: 49-57.

Mount, T. 1994. Climate change and agriculture: A perspective on priorities for economic policy, Climatic Change 27(1): 121-38.

Naess, L. O., G. Bang, S. Eriksen, and J. Vevatne. 2005. Institutional adaptation to climate change: Flood responses at the municipal level in Norway. Global Environmental Change 15: 125-38.

Naylor, R., W. Falcon, E. Zavaleta. 1997. Variability and growth in grain yields, 1950-94. Does the record point to greater instability? Population and Development Review 23(1): 41-58.

Nicholls, R.J., P.P. Wong, V.R. Burkett, J.O. Codignotto, J.E. Hay, R.F. McLean, S. Ragoonaden and C.D. Woodroffe, 2007: Coastal systems and low-lying areas. Climate Change 2007: Impacts, Adaptation and Vulnerability. Contribution of Working Group II to the Fourth Assessment Report of the Intergovernmental Panel on Climate Change, M.L. Parry, O.F. Canziani, J.P. Palutikof, P.J. van der Linden and C.E. Hanson, Eds., Cambridge University Press, Cambridge, UK, 315-356.

Norton, A. and M. Foster. 2001. The potential of using sustainable livelihoods approaches in poverty reduction strategy papers. Working Paper 148. London: Overseas Development Institute (ODI). Pp. 44.

Nyong, A., F. Adesina, and B. O. Elasha. 2007. The value of indigenous knowledge in climate change mitigation and adaptation strategies in the African Sahel. Mitigation and Adaptation Strategies in Global Change 12: 787-97.

O'Brien. K. L, and R.M. Leichenko, Double exposure: Assessing the impacts of climate change within the context of economic globalization, Global Environmental Change 10 (2000) (3), pp. 221-232.

O’Brien, K., R. Leichenko, U. Kelkar, H. Venema, G. Aandahl and H. Tompkins et al. 2004. Mapping vulnerability to multiple stressors: climate change and globalization in India, Global Environmental Change 14(4): 303-13.

Ostrom, E. 1990. Governing the Commons: The Evolution of Institutions for Collective Action. Cambridge: Cambridge University Press.

Pielke, R. A. J.. 1998. Rethinking the role of adaptation in climate policy. Global Environmental Change 8: $159-70$.

Pimentel, D. 1999. Predicting global change: climate change and the global harvest: potential impacts of the greenhouse effect on agriculture. Trends in Ecology and Evolution 14 (11) (1999) 454-455.

Pimm, S.L., 1984. The complexity and stability of ecosystems. Nature 307 (26): 321-326.

Reid, P. and C. Vogel. 2006. Living and responding to multiple stressors in South Africa - Glimpses from KwaZulu-Natal. Global Environmental Change 16(2): 195-206.

Rosenberg, N.J., 1992. Adaptation of agriculture to climate change. Climatic Change 21 (4): 385-405.

Rosenzweig, C., and M. Parry. 1994. Potential impact of climate change on world food supply. Nature 367: $133-38$.

Sandford, S. 1983. Management of Pastoral Development in the Third World. Chichester: John Wiley. 
Schachhuber, A. 2004. Social movements, environmental governance, and rural territorial development: An international perspective. York University, Mimeo.

Schneider, Stephen H., and Janica Cane. 2006. Dangers and thresholds in climate change and the implications for justice. In Fairness in Adaptation to Climate Change. W. Neil Adger, Jouni Paavola, Saleemul Huq, and M. J. Mace (eds). Pp. 23-51. Cambridge: The MIT Press.

Scoones, Ian. (ed). 2001. Dynamics and Diversity: Soil Fertility and Farming Livelihoods in Africa. London: Earthscan.

Scoones, Ian. 1998. Sustainable Rural Livelihoods: a framework for analysis. IDS Working Paper no. 72, Brighton: Institute for Development Studies.

Sen, A. 1981. Ingredients of famine analysis: Availability and entitlements, The Quarterly Journal of Economics 96 (3): 433-63.

Shepherd, P., J. Tansey, and H. Dowlatabadi. 2006. Context matters: What shapes adaptation to water stress in the Okanagan? Climatic Change 78(1). DOI: 10.1007/s10584-006-9093-7.

Smit, B., Wandel, J., 2006. Adaptation, adaptive capacity and vulnerability. Global Environmental Change 16(3): 282-92.

Smit, B. and O. Polifosova. 2001. Adaptation to climate change in the context of sustainable development and equity. Climate Change 2001: Impacts, Adaptation and Vulnerability. Contribution of Working Group II to the Third Assessment report of the Intergovernmental Panel on Climate Change.

Smit, B., McNabb, D., Smithers, J., 1996. Agricultural adaptation to climatic variation. Climatic Change 33 (1): 7-29.

Smit, B., I. Burton, R. Klein and J. Wandel. 2000. An anatomy of adaptation to climate change and variability, Climatic Change 45(1): 223-51.

Smit, B., I. Burton, R. J. T. Klein, and R. Street. 1999. The science of adaptation: A framework for assessment. Mitigation and Adaptation Strategies for Global Change 4 (3-4): 199-213.

Smith, J.B., Lenhart, S.S., 1996. Climate change adaptation policy options. Climate Research 6(2): 193201.

Smithers, J., Smit, B., 1997. Human adaptation to climatic variability and change. Global Environmental Change 7 (2): 129-46.

Tarhule, A., and P. J. Lamb. 2003. Climate research and seasonal forecasting for West Africans:

Perceptions, dissemination, and use. Bulletin of the American Meteorological Society 84:1741-59

Thomas, David S. G. and Chasca Twyman. 2006. Adaptation and equity in resource dependent societies. In Fairness in Adaptation to Climate Change. W. Neil Adger, Jouni Paavola, Saleemul Huq, and M. J. Mace (eds). Pp. 223-37. Cambridge: The MIT Press.

Thompson A., P. Robbins, B. Sohngen, J. Arvai, and T. Koontz. 2006. Economy, politics, and institutions : From adaptation to adaptive management in climate change. Climatic Change 78(1): 1-5.

Tickell, C. 1990. Environmental Refugees: The Human Impact of Global Climate Change. National Environment Research Council, Swindon, UK

Timmerman, P. 1981. Vulnerability, Resilience and the Collapse of Society. Environmental Monograph 1, Institute for Environmental Studies, Toronto University.

Tol, R. S. J., T. E. Downing, O. J. Kuik, and J. B. Smith. 2004. Distributional aspects of climate change impacts. Global Environmental Change 14: 259-72. 
Tompkins, E. L. and W. N. Adger. 2004. Does adaptive management of natural resources enhance resilience to climate change? Ecology and Society 9(2): 10. [online] URL:

http://www.ecologyandsociety.org/vol9/iss2/art10.

Tompkins, E., M.C. Lemos and E. Boyd (in review). The less disastrous disaster: Managing response to climate-driven hazard in the Cayman Islands and NE Brazil. Global Environmental Change.

Tompkins, E., W. N. Adger, and K. Brown. 2002. Institutional networks for inclusive coastal management in Trinidad and Tobago. Environment and Planning A 34:1095-1111.

Turner, B. L. II, R.E. Kasperson, P.A. Matson, J.J. McCarthy, R.W. Corell and L. Christensen et al. 2003. A framework for vulnerability analysis in sustainability science, PNAS 100(14): 8074-79.

Uphoff, N. and L. Buck. 2006. Strengthening rural local institutional capacities for sustainable livelihoods and equitable development. Paper prepared for the Social Development Department of the World Bank. Mimeo.

Wade, R. 1994. Village Republics: Economic Conditions for Collective Action in South India. Oakland: ICS Press.

Wandiga, S. O., M. Opondo, D.Olago, et al. 2006. Vulnerability to climate-induced highland malaria in East Africa. AIACC Working Paper No. 26. Washington DC: International START Secretariat.

Watson, Robert T., Marufu C. Zinyowera, and Richard H. Moss. 1998. New York: Cambridge University Press.

Watts, M. 1983. Hazards and crises: A political economy of drought and famine in Northern Nigeria, Antipode 15(1): 24-34.

Watts, M.J. and H. G. Bohle, 1993. The space of vulnerability: The causal structure of hunger and famine. Progress in Human Geography 17 (1), 43-67.

World Bank. 2005. Index-Based Livestock Insurance Project, Project Appraisal Document. Rural Development and Natural Resource Sector Unit, EAP. Washington, DC: The World Bank.

World Bank. Forthcoming. Mainstreaming Climate Risk Management and Adaptation to Climate Change in Development Projects. Quick reference guidance notes with special focus on agricultural, NRM and rural development projects. Environment Department. Forthcoming.

Yohe, G. and R. Tol. 2001. Indicators for social and economic coping capacity moving toward a working definition of adaptive capacity. Global Environmental Change 12: 25-40.

Young, K. R., and J. K. Lipton. 2006. Adaptive governance and climate change in the tropical highlands of western South America. Climatic Change 78: 63-102.

Zheng, Y. R., Z. X. Xie, C. Robert, et al. 2006. Did climate drive ecosystem change and induce desertification in Orindang sandy land, China over the past 40 years? Journal of Arid Environments 64(3): 523-41.

Ziervogel, G. and R. Calder, R.. 2003. Climate variability and rural livelihoods: Assessing the impact of seasonal climate forecasts in Lesotho. Area 35(4): 403-17. 


\section{Number of Adaptation Projects per Country}

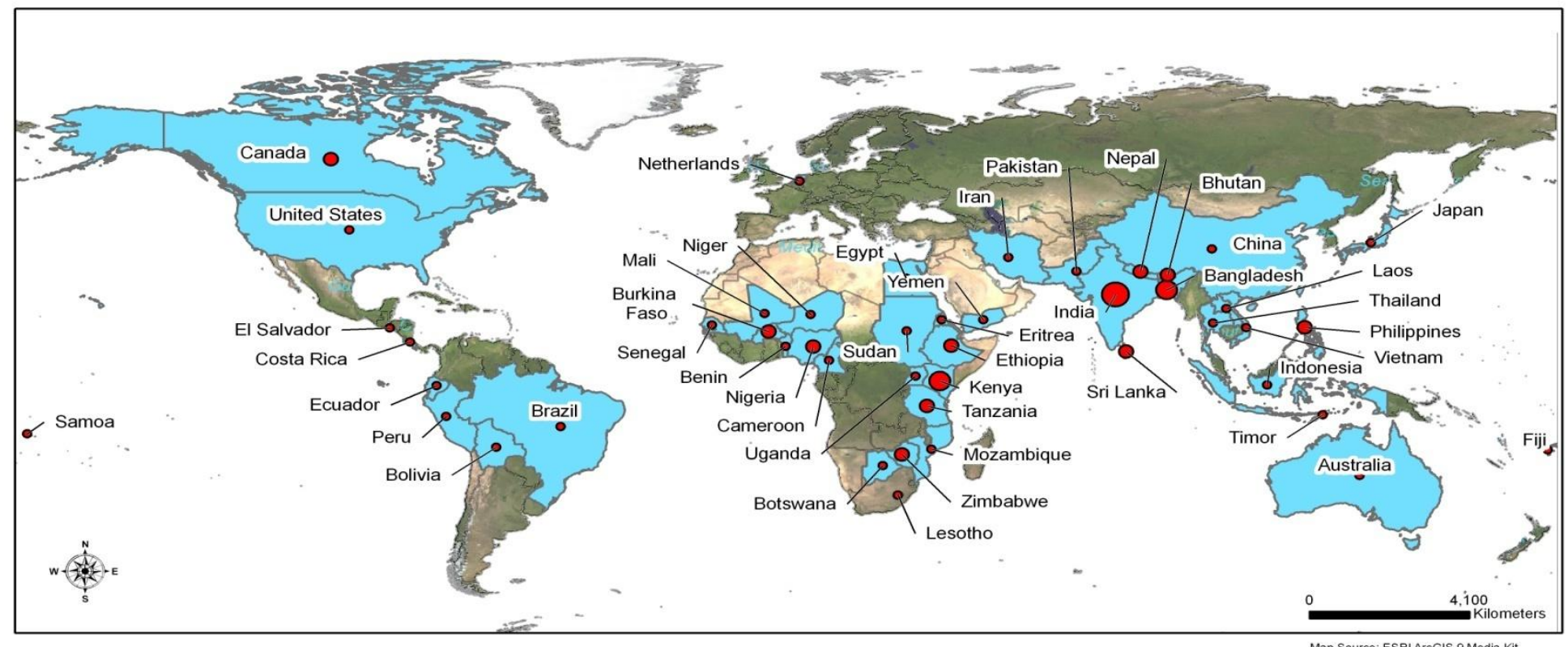

Countries with

Number of Projects Per Country

Adaptation Projects

- $\quad 3-5 \bigcirc>10$

Annex Figure 1: Distribution of adaptation cases in the UNFCCC Coping Strategies Database 
${ }^{1}$ But see Glantz 1990. Climate change began to take on significant international policy significance especially after 1995 when the second assessment report of the Inter-Governmental Panel on Climate Change (IPCC) announced that "human activities were having a 'discernible' impact on climate" (Schneider and Lane 2006: 25). See also Watson et al. 1998 and Hardy 2003. Some observers argue that the IPCC's estimates of warming and its likely disastrous impacts may in fact be conservative.

${ }^{2}$ This note uses "rural poor" as a general term to refer to the more marginalized and disadvantaged, and often the most vulnerable social groups in rural areas.

${ }^{3}$ This uncertainty is primarily the result of the scale at which projections about climate change can be made through General Circulation Models (GCMs), the main source of information about future changes in climate.

${ }^{4}$ In focusing on both adjustment and coping strategies, the paper broadly follows the definition of adaptation as used by the Inter-Governmental Panel of Climate Change (Adger et al. 2007: 719-20).

${ }^{5}$ Adger et al. 2007: 396 provide a somewhat different justification for the need to adapt.

${ }^{6}$ The UNFCCC has developed a database on local coping and adaptation strategies that provides selected information on adaptation practices, external interventions, and local institutions from nearly 40 countries. It is the most comprehensive database on adaptation strategies in existence and forms a useful basis for a systematic examination of adaptation strategies globally.

${ }^{7}$ The total number of discrete cases in the UNFCCC database is 138 . However, a number of the cases are essentially duplication of information, especially in the water harvesting and forest sector. To reduce redundancy, I eliminated some of the cases that did not bring any new information to bear on the analysis.

${ }^{8}$ Note that the UNFCCC database does not provide cases of wage labor diversification and mobility or agropastoralist migration as instances of adaptation strategies. 